\title{
Enhancement of Flame Retardancy and Mechanical Properties of Polylactic Acid with a Biodegradable Fire-Retardant Filler System Based on Bamboo Charcoal
}

\author{
Wenzhu Li ${ }^{1,+}$, Liang Zhang ${ }^{1,+}$, Weisheng Chai ${ }^{1}$, Ningning Yin ${ }^{1}$, Kate Semple ${ }^{2}$, Lu Li ${ }^{1}$, Wenbiao Zhang ${ }^{1, *}$ \\ and Chunping Dai ${ }^{2, *(1)}$
}

check for

updates

Citation: Li, W.; Zhang, L.; Chai, W.; Yin, N.; Semple, K.; Li, L.; Zhang, W.; Dai, C. Enhancement of Flame

Retardancy and Mechanical

Properties of Polylactic Acid with a Biodegradable Fire-Retardant Filler System Based on Bamboo Charcoal Polymers 2021, 13, 2167. https:// doi.org/10.3390/polym13132167

Academic Editor: Antonios Papadopoulos

Received: 7 June 2021

Accepted: 27 June 2021

Published: 30 June 2021

Publisher's Note: MDPI stays neutral with regard to jurisdictional claims in published maps and institutional affiliations.

Copyright: (c) 2021 by the authors. Licensee MDPI, Basel, Switzerland. This article is an open access article distributed under the terms and conditions of the Creative Commons Attribution (CC BY) license (https:/ / creativecommons.org/licenses/by/ $4.0 /)$.
1 Zhejiang Provincial Collaborative Innovation Center for Bamboo Resources and High-Efficiency Utilization, College of Chemistry and Materials Engineering, Zhejiang A\&F University, Hangzhou 311300, China; lwz@zafu.edu.cn (W.L.); chaselz520103@163.com (L.Z.); shinkuu1995@163.com (W.C.); ynn8520@163.com (N.Y.); lilu@zafu.edu.cn (L.L.)

2 Department of Wood Science, Faculty of Forestry, University of British Columbia, 2900-2424 Main Mall, Vancouver, BC V6T 1Z4, Canada; katherine.semple@ubc.ca

* Correspondence: zwb@zafu.edu.cn (W.Z.); chunping.dai@ubc.ca (C.D.); Tel.: +86-139-6802-5939 (W.Z.); +1-604-827-6047 (C.D.)

+ These authors contributed equally to this work.

Abstract: A cooperative flame-retardant system based on natural intumescent-grafted bamboo charcoal (BC) and chitosan (CS) was developed for polylactic acid (PLA) with improved flame retardancy and minimal decline in strength properties. Chitosan (CS) as an adhesion promoter improved the interfacial compatibility between graft-modified bamboo charcoal (BC-m) and PLA leading to enhanced tensile properties by $11.11 \%$ and $8.42 \%$, respectively for tensile strength and modulus. At 3 wt. $\%$ CS and $30 \mathrm{wt} . \%$ BC-m, the crystallinity of the composite increased to $38.92 \%$, or 43 times that of pure PLA $(0.9 \%)$. CS promotes the reorganization of the internal crystal structure. Thermogravimetric analysis showed significantly improved material retention of PLA composites in nitrogen and air atmosphere. Residue rate for $5 \mathrm{wt} . \%$ CS and $30 \mathrm{wt} . \%$ BC-m was $29.42 \%$ which is $55.1 \%$ higher than the theoretical value of $18.97 \%$. Flammability tests (limiting oxygen indexLOI and UL-94) indicated significantly improved flame retardancy and evidence of cooperation between CS and BC-m, with calculated cooperative effectiveness index $(\mathrm{Ce})>1$. From CONE tests, the peak heat release rate (pHRR) and total heat release (THR) were reduced by $26.9 \%$ and $30.5 \%$, respectively, for $3 \%$ CS $+20 \%$ BC-m in PLA compared with adding 20\% BC-m alone. Analysis of carbon residue morphology, chemical elements and structure suggest CS and BC-m form a more stable char containing pyrophosphate. This char provides heat insulation to inhibit complete polymer pyrolysis, resulting in improved flame retardancy of PLA composites. Optimal mix may be recommended at $20 \% \mathrm{BC}-\mathrm{m}+3 \% \mathrm{CS}$ to balance compatibility, composite strength properties and flame retardance.

Keywords: bamboo charcoal; chitosan; polylactic acid; flame retardant; cooperative system

\section{Introduction}

Universal dependence on petroleum-based plastics has created enormous land and sea pollution problems prompting research and development of new bio-based and biodegradable polymers [1,2]. Polylactic acid (PLA) is an example, with excellent mechanical properties, high processability, and potential for regeneration and biodegradability [3,4], and is today widely used in packaging, the medical industry, and 3D printing [5-8]. However, its inherent biodegradability and fermented biomass-derived carbon-hydrogen composition give PLA low heat and melt resistance when burned [9-11], causing flame spread due to melting and dripping [12]. For this reason, PLA does not meet the UL-94 V-1 rating or higher required to mitigate fire hazard, limiting its applications [13]. 
Various strategies have been proposed to improve the flame retardancy of PLA $[14,15]$. Previous work by authors include modification with aluminum hypophosphite (AHP) $[16,17]$ and bamboo charcoal (BC) [18]. The flame-retardant performance was improved, but mechanical properties decreased and combustion produced toxic phosphene gas $\left(\mathrm{PH}_{3}\right)$. While BC+AHP was effective in PLA, it is not commercially viable as a "green" packaging material. Renewable, bio-based, non- or low-toxic and low-smoke intumescent flame retardants (IFR) are being developed [7,19]. Biomass materials, such as starch, lignin, chitosan (CS), and sodium alginate [20,21], have been investigated as flame-retardant charring agents in polymers. A new bio-based flame retardant (defined as LHP) containing hydroxyapatite and lignocellulose in a ratio of LHP to APP of 1:3 at $10 \mathrm{wt} . \%$ addition is effective [14]. The peak heat release value in cone calorimeter combustion (CONE) tests decreased from $365 \mathrm{~kW} / \mathrm{m}^{2}$ to $250 \mathrm{~kW} / \mathrm{m}^{2}$. Beta-cyclodextrin $(\beta-C D)$ and poly (propylene glycol) (PPG) have been used to improve the flame retardancy of PLA with ammonium polyphosphate (APP) and melamine (MA) [22]. A limiting oxygen index (LOI) of $34 \mathrm{vol} \%$ and a UL-94 V-0 vertical flame test rating were both achieved. Besides, the addition of $1-5 \mathrm{wt} . \%$ starch was also used to further increase the LOI to $30.6 \%$ and improve the anti-dripping properties of PLA-based foams [23]. However, these additives require a high loading for efficacy which significantly reduces the mechanical properties of the materials [24,25].

Chitosan (CS), the fully or partially deacetylated form of chitin, is one of the very few natural polymers that has a primary amino group along its main chain [26]. It has excellent biocompatibility, film-forming properties, and different viscosity states, and is therefore used as the reinforcing phase in polymer composites [27-29]. CS on its own has little flame retardancy with a carbohydrate structure that does not promote carbonization; however, its matrix can be modified with inorganic nanofillers to give unique properties. For example, adding halloysite can significantly raise the ignition temperature to around $150{ }^{\circ} \mathrm{C}$, although a large number of active layers are needed [30,31]. Though the flame retardancy of CS can be increased by the formation of a carbon layer in the presence of phosphoric acid [21,32,33], phosphorylated chitosan (CS-P) often displays poor thermal stability, which limits its application in many polymers [34]. However CS in different states may be used to form a cooperative system with a char-forming intumescent graftmodified BC, developed by Zhang et al. (2021) [18]. BC has a very high specific surface area and a rich, irregular pore structure that is effectively graft modified with phosphorous and nitrogen compounds to produce an effective flame retardant that mixes well with PLA. The objective of this work was to develop and test a non-toxic, more effective, and biodegradable flame-retardant system based on combining BC-m with CS with minimal negative impacts on the mechanical properties of polylactic acid.

\section{Materials and Methods}

\subsection{Materials}

PLA resin was purchased from Cargill Dow Inc (4032D, Nature Works Co. Ltd., Blair, NE, USA) with a density of $1.24 \mathrm{~g} / \mathrm{cm}^{3}$ and melting point of $160^{\circ} \mathrm{C}$. The glass transition temperature and the crystallization peak temperature of the polymer are $57.8^{\circ} \mathrm{C}$ and $150-170{ }^{\circ} \mathrm{C}$, respectively. BC was supplied by Zhejiang Anji Huasen Bamboo Charcoal Products Co., Ltd. (Zhejiang, China). The product was carbonized at 700 to $800{ }^{\circ} \mathrm{C}$ and ground to 100 to 250 mesh particle size. CS was supplied by Macklin Biochemical Co., Ltd., (Shanghai, China), with viscosity of $200-400 \mathrm{mPa} . \mathrm{s}$.

Chemical reagents used for graft modification of $B C$ were: hydrogen peroxide $\left(\mathrm{H}_{2} \mathrm{O}_{2}\right)$ at 30\% conc. (Yonghua Chemical Reagent Co., Ltd., Jiangsu, China), phosphoric acid (PA) at $85 \%$ conc. and urea at $99 \%$ purity (both from Sinopharm Chemical Reagent Co., Ltd., Shanghai, China), and ammonium hydroxide solution at $3 \%$ conc. and $0.91 \mathrm{~g} / \mathrm{mL}$ density at $20{ }^{\circ} \mathrm{C}$ (Macklin Biochemical Co., Ltd., Shanghai, China). 


\subsection{Preparation}

\subsubsection{Grafting Modification of $\mathrm{BC}$}

As described in previous work [18], two batches of $30 \%$ conc. aqueous $\mathrm{H}_{2} \mathrm{O}_{2}$ solution were used to treat $\mathrm{BC}$ (which was thoroughly washed and dried) in succession. Using a $\mathrm{BC}$ to $\mathrm{H}_{2} \mathrm{O}_{2}$ of 1:3, the $\mathrm{BC}$ was treated for $8 \mathrm{~h}$. After filtration, $\mathrm{H}_{2} \mathrm{O}_{2}$ was added again, followed by $1 \mathrm{~h}$ of microwave irradiation at $200 \mathrm{~W}$, and oven drying at $90{ }^{\circ} \mathrm{C}$ overnight to produce a treated $\mathrm{BC}$ intermediate termed "BC-o".

The BC-o powder was reacted with PA at $85 \%$ conc. using a 1:1 ratio to BC-o and stirring at $80^{\circ} \mathrm{C}$ for $30 \mathrm{~min}$, then gradually heated further to $100{ }^{\circ} \mathrm{C}$ and maintained for $1 \mathrm{~h}$. Urea dispersed in deionized water was added for a PA:urea ratio of $1: 1.8$, with $3 \%$ ammonia used to adjust the $\mathrm{pH}$ of the mixture to between 8 and 10. The mixture was heated slowly to $120^{\circ} \mathrm{C}$ for $30 \mathrm{~min}$ and then gradually increased to $160{ }^{\circ} \mathrm{C}$, which was then cured in an oven at $200^{\circ} \mathrm{C}$ for $6 \mathrm{~h}$. The hardened foam, termed "BC-m", was ground to 150-250 mesh and washed several times with a hot ethanol solution and dried at $90^{\circ} \mathrm{C}$ for $2 \mathrm{~h}$.

\subsubsection{Preparation of Flame-Retardant PLA Composites}

PLA, CS, and BC-m powders were dried at $80^{\circ} \mathrm{C}$ overnight. A twin-roll mixing mill (XK-160, Wuhan, China) was used to compound them together at $180^{\circ} \mathrm{C}$. The screw was run at $30 \mathrm{rpm}$. Different mix ratios of PLA, CS, and BC-m (shown in Table 1) were prepared.

Table 1. Formulations for PLA and its blends.

\begin{tabular}{cccc}
\hline & \multicolumn{3}{c}{ Composition (wt. \%) } \\
\cline { 2 - 4 } Scheme 100 & PLA & BC-m & CS \\
\hline PLA & 100 & 0 & 0 \\
FPLA-C3 & 97 & 0 & 3 \\
FPLA-C5 & 95 & 0 & 5 \\
FPLA-B1 & 90 & 10 & 0 \\
FPLA-B2 & 80 & 20 & 0 \\
FPLA-B3 & 70 & 30 & 0 \\
FPLA-C31 & 87 & 10 & 3 \\
FPLA-C32 & 77 & 20 & 3 \\
FPLA-C33 & 67 & 30 & 3 \\
FPLA-C51 & 85 & 10 & 5 \\
FPLA-C52 & 75 & 20 & 5 \\
FPLA-C53 & 65 & 30 & 5 \\
\hline
\end{tabular}

The compounded, extruded mixes were cut into pellets and re-mixed in the mill until a visually good dispersion was achieved. The compounded pellets were hot-pressed $\left(180^{\circ} \mathrm{C}\right)$ into sheets with under $10 \mathrm{MPa}$ pressure for $10 \mathrm{~min}$ for combustion performance tests. Pellets were also injection molded into splines at $175^{\circ} \mathrm{C}$ and $6 \mathrm{MPa}$ pressure, which were used for mechanical tests of tensile and flexural properties. A schematic diagram of the preparation and testing processes is shown in Figure 1.

\subsection{Measurement and Characterization}

\subsubsection{Characterization of PLA Composites}

The fracture surface morphology of PLA and the blends with BC-m and CS were observed by a scanning electron microscope (SEM; TM3030, Hitachi, Japan) at an accelerating voltage of $15 \mathrm{kV}$. Samples were conductive coated by gold sputter coating for $90 \mathrm{~s}$ at a current of $15 \mathrm{~mA}$ to get a conductive layer. 


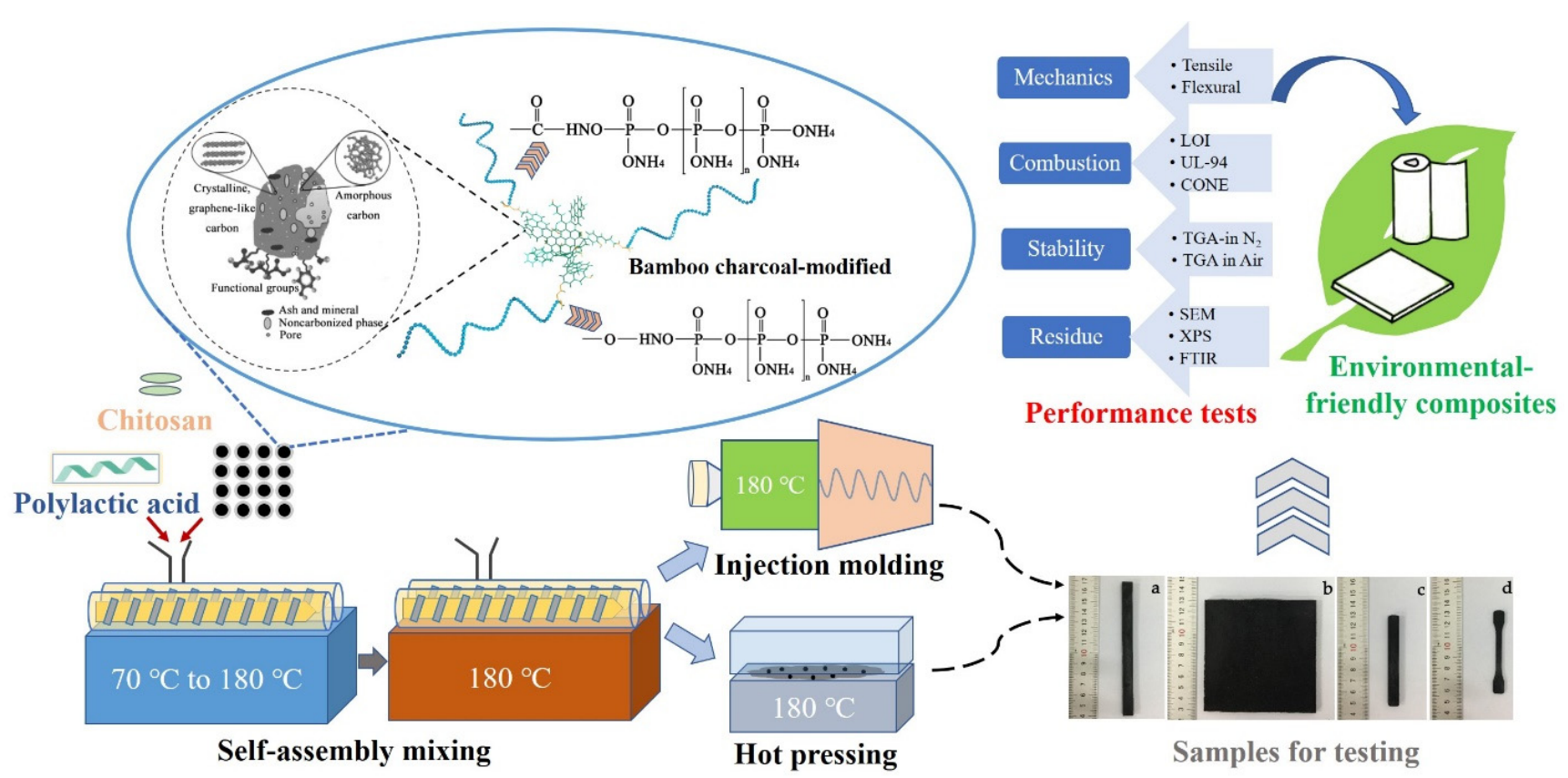

Figure 1. Schematic diagram of composite preparation and testing.

An X-ray diffractometer (XRD6000, Shimadzu Co., Ltd., Kyoto, Japan) was used to detect changes in the crystal structure. The profiles were analyzed by $\mathrm{Cu} \mathrm{K} \alpha(0.15406 \mathrm{~nm})$ radiation under a tube voltage of $40 \mathrm{kV}$. The tube current was set at $30 \mathrm{~mA}$, and the scanning range was $3^{\circ}-40^{\circ}(2 \theta)$ at a rate of $2^{\circ} / \mathrm{min}$.

Differential scanning calorimetry (DSC) tests were conducted using DSC-500B (YANJIN Scientific Instrument Co., Ltd., Shanghai, China) under nitrogen at a flow rate of $50 \mathrm{~mL} / \mathrm{min}$. Samples of $5 \mathrm{mg}$ were weighed and sealed in a tared aluminum pan with an empty pan used as the reference. Samples were first heated from 25 to $220^{\circ} \mathrm{C}$ at a rate of $10{ }^{\circ} \mathrm{C} / \mathrm{min}^{-1}$, kept for $5 \mathrm{~min}$ to eliminate the thermal history, then cooled down to $25^{\circ} \mathrm{C}$ at a rate of $10^{\circ} \mathrm{C} / \mathrm{min}$. The second heating curve was recorded at a heating rate of $10^{\circ} \mathrm{C} / \mathrm{min}$, showing the melting process. Crystallinity $\left(X_{\mathrm{c}}\right)$ was estimated according to Equation (1),

$$
X_{\mathrm{c}}(\%)=\frac{\triangle H_{\mathrm{C}}}{\triangle H_{0} \cdot X_{\mathrm{PLA}}} \times 100 \%
$$

where $\triangle H_{C}$ refers to the crystallization enthalpy; $\triangle H_{0}$ refers to the enthalpy value during $100 \%$ crystallization of PLA, which is $93.6 \mathrm{~J} / \mathrm{g}$ [35]; $X_{\text {PLA }}$ refers to the weight ratio of PLA in the FPLA composite blends.

\subsubsection{Mechanical Properties}

The mechanical properties (tensile strength and modulus, MOR, MOE) of the composites were tested using a microcomputer-controlled electronic universal testing machine (CMT610, MTS Industrial System (China) Co., Ltd., Shanghai, China) according to the Chinese National Testing Standard GB/T 1040-2006 (for tensile properties) and GB/T 9341-2008 (for flexural properties). For the tensile test, the width and thickness of the narrow stress zone in specimens were 5 and $2 \mathrm{~mm}$, respectively. The gauge length was set to $60 \mathrm{~mm}$ and loading speed was $2 \mathrm{~mm} / \mathrm{min}$. The flexural test specimen dimensions were $80 \times 10 \times 4 \mathrm{~mm}^{3}$ with load span of $60 \mathrm{~mm}$ and loading speed of $2 \mathrm{~mm} / \mathrm{min}$.

\subsubsection{Thermal Behavior}

Thermal gravimetric analysis (TGA) was carried out using a thermo-gravimetric analyzer (F1, NETZSCH Co., Ltd., Selbu, Germany) under nitrogen and air atmosphere. Approximately $5-10 \mathrm{mg}$ of material was weighed and assayed in an aluminum crucible 
and tested over a temperature range of 50 to $700{ }^{\circ} \mathrm{C}$ with a heating rate of $10{ }^{\circ} \mathrm{C} / \mathrm{min}$ under a gas flow of $20 \mathrm{~mL} / \mathrm{min}$. An empty crucible was used as a reference.

\subsubsection{Combustion Properties Tests}

The limiting oxygen index (LOI), expressed as vol.\% minimum concentration of oxygen required to initiate combustion, was measured using a JF-3 oxygen index meter (Jiangning Analysis Instrument Company, Nanjing, Jiangsu, China) according to ISO 4589-2:2017 [36]. The dimensions of the test specimens were $100 \times 10 \times 4 \mathrm{~mm}^{3}$.

The Underwriters Laboratory (UL-94) vertical flame test was carried out using a 5402type vertical burn test instrument (Suzhou Yangyi Woerqi Detection Technology Co., Ltd., Nanjing, Jiangsu, China) with specimens measuring $130 \times 13 \times 3 \mathrm{~mm}^{3}$. The test parameters and ratings are defined in ATSM D3801-10 [37].

Cone calorimeter combustion (CONE) tests were carried out using a cone calorimeter (FTT0007, Fire Testing Technology Co., Ltd., East Grinstead, UK) according to ISO 56601 [38]. The specimen measuring $100 \times 100 \times 4 \mathrm{~mm}^{3}$ was placed horizontally in a bed of aluminum foil and was heated under the combustion hood in which the predetermined test height was $25 \mathrm{~cm}$. Using an external heat flux of $35 \mathrm{~kW} / \mathrm{m}^{2}$, the material was ignited and the relevant combustion performance indices recorded until combustion was complete. Combustion indices are the average of 3 test specimens per group.

\subsubsection{Residue Analysis}

All remaining carbonized residues from the CONE tests were collected and imaged to further analyze the surface morphology using a scanning electron microscope (SEM) at an accelerating voltage of $15 \mathrm{kV}$. Specimens were sputter coated with $24 \mathrm{ct}$ gold for $90 \mathrm{~s}$ at a current of $15 \mathrm{~mA}$.

Fourier transform infrared spectroscopy (FTIR) was used to detect the changes in chemical groups and structure of the residues using a Nicolet 6700FT-IR spectrophotometer with $\mathrm{KBr}$ slice. The transmission mode was used and the wave number range was set from $400 \mathrm{~cm}^{-1}$ to $4000 \mathrm{~cm}^{-1}$.

X-ray photoelectron spectroscopy (XPS) was used to investigate the residual element contents of samples. This was carried out using a Thermo Scientific ${ }^{\mathrm{TM}} \mathrm{K}-\mathrm{Alpha}{ }^{\mathrm{TM}+}$ spec- $^{-}$ trometer (Thermo Fisher, Scientific Inc, Waltham, MA, USA) equipped with a monochromatic $\mathrm{Al} \mathrm{K} \alpha \mathrm{X}$-ray source $(1486.6 \mathrm{eV})$ operating at $100 \mathrm{~W}$. Samples were analyzed under vacuum $\left(p<10^{-8}\right.$ mbar) with a pass energy of $150 \mathrm{eV}$ (survey scans) or $25 \mathrm{eV}$ (highresolution scans). All peaks were calibrated with C1s peak binding energy at $284.8 \mathrm{eV}$ for adventitious carbon. The experimental peaks were fitted using Avantage software.

\section{Results}

\subsection{Characterization of PLA and FPLA Composites}

\subsubsection{Micromorphology and Dispersibility}

The surface morphology of BC and BC-m are shown in Figure 2. The original pore structure of the bamboo tissue can be clearly seen on the surface of $B C$ particles (Figure 2a), while the surface of BC-m became amorphous (Figure $2 b$ ). There was little difference in particle size of $\mathrm{BC}$ before and after modification, which was mainly between 50 and $100 \mu \mathrm{m}$.

To investigate the dispersion in PLA, observation under SEM at low magnification $(120 \times)$ was performed and the corresponding images are shown in Figure 3. Figure $3 a_{1}-3 a_{3}$ show the fracture surface morphology with different $\mathrm{BC}-\mathrm{m}$ addition levels indicating uniform distribution of BC-m in the polymer. At higher levels of BC-m (30\%), the localized agglomeration of particles was evident (Figure $3 \mathrm{a}_{2}$ ) leading to a weak polymer-filler interface. The typical particle size of BC-m at the fracture surface was also analyzed, with results shown in Figure 4. A smaller particle size (mostly 20-26 $\mu \mathrm{m}$ ) was observed due to cyclic extrusion of the screw during the melt compounding process. 

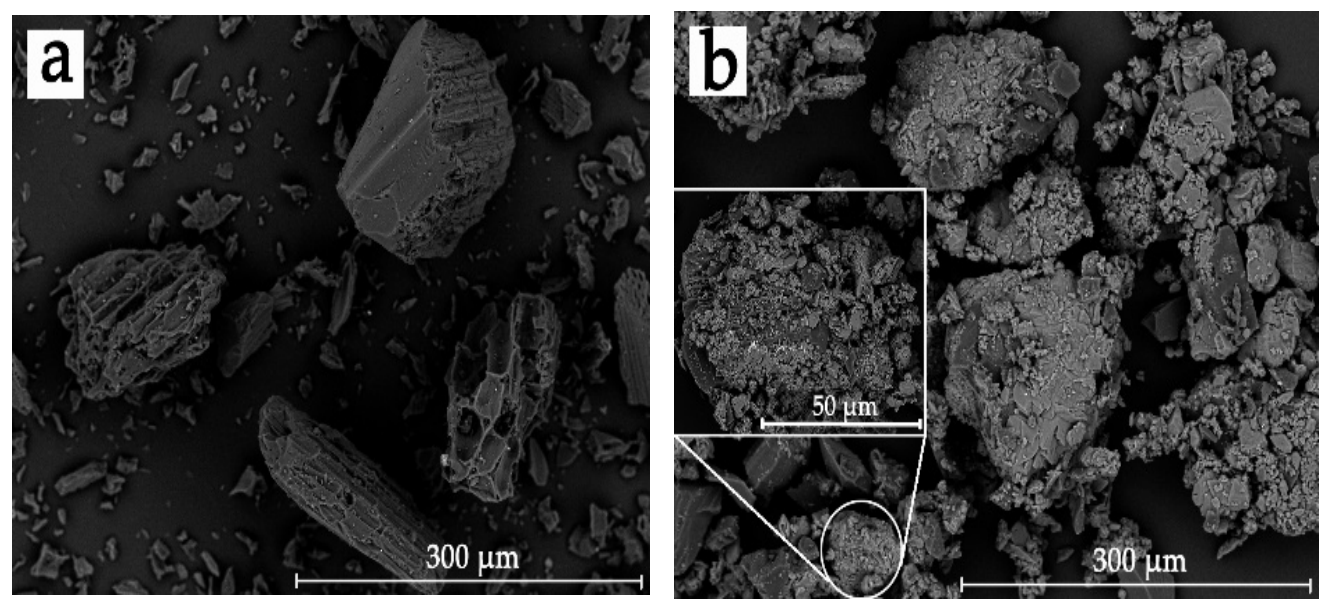

Figure 2. SEM images of surface morphology: (a) BC and (b) BC-m.

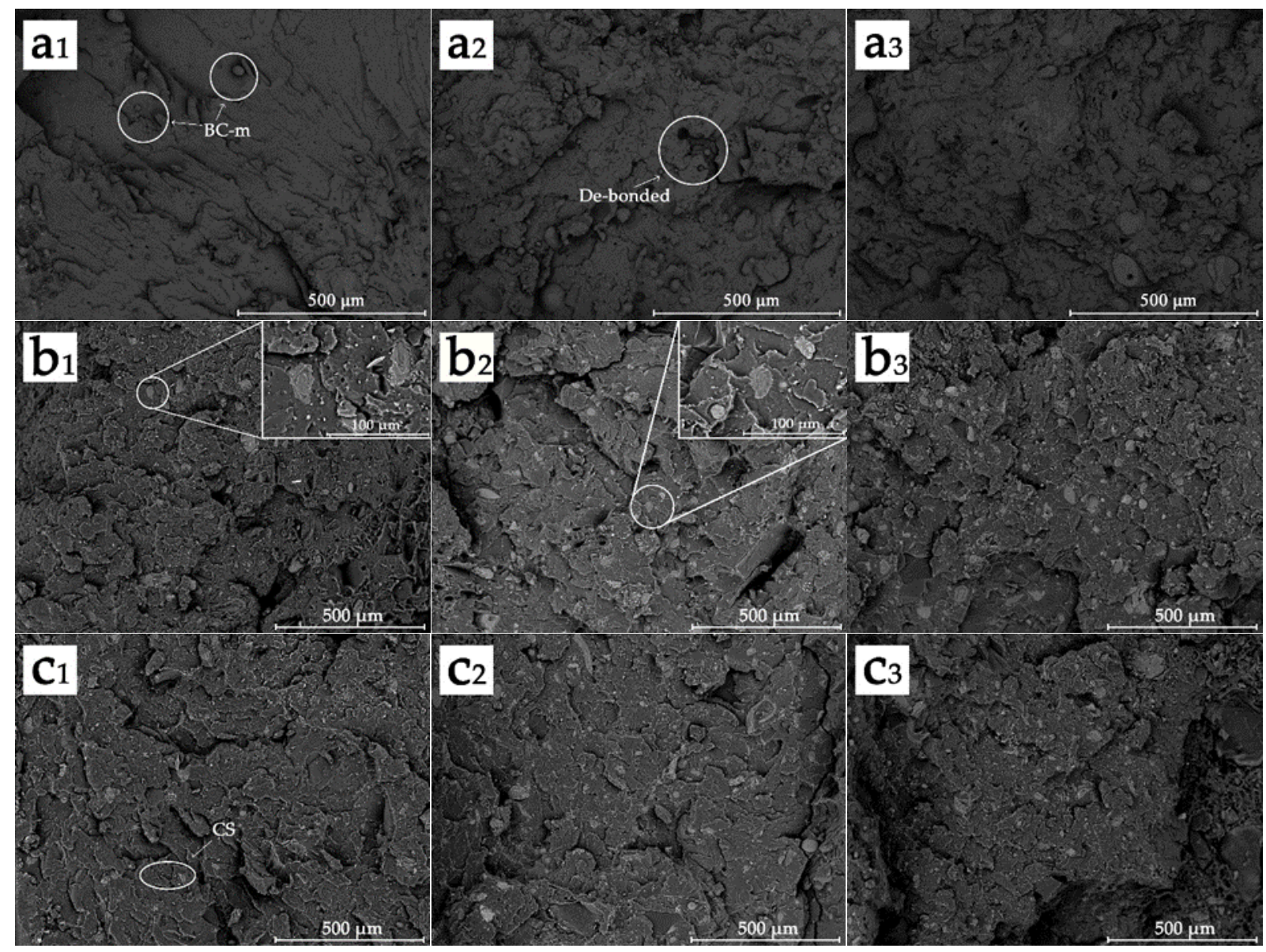

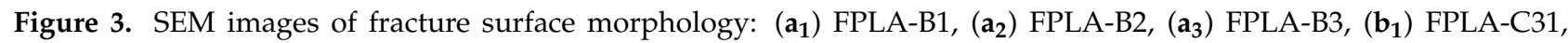
$\left(\mathbf{b}_{2}\right)$ FPLA-C32, $\left(\mathbf{b}_{3}\right)$ FPLA-C33, $\left(\mathbf{c}_{\mathbf{1}}\right)$ FPLA-C51, $\left(\mathbf{c}_{2}\right)$ FPLA-C52, and $\left(\mathbf{c}_{3}\right)$ FPLA-C53. 


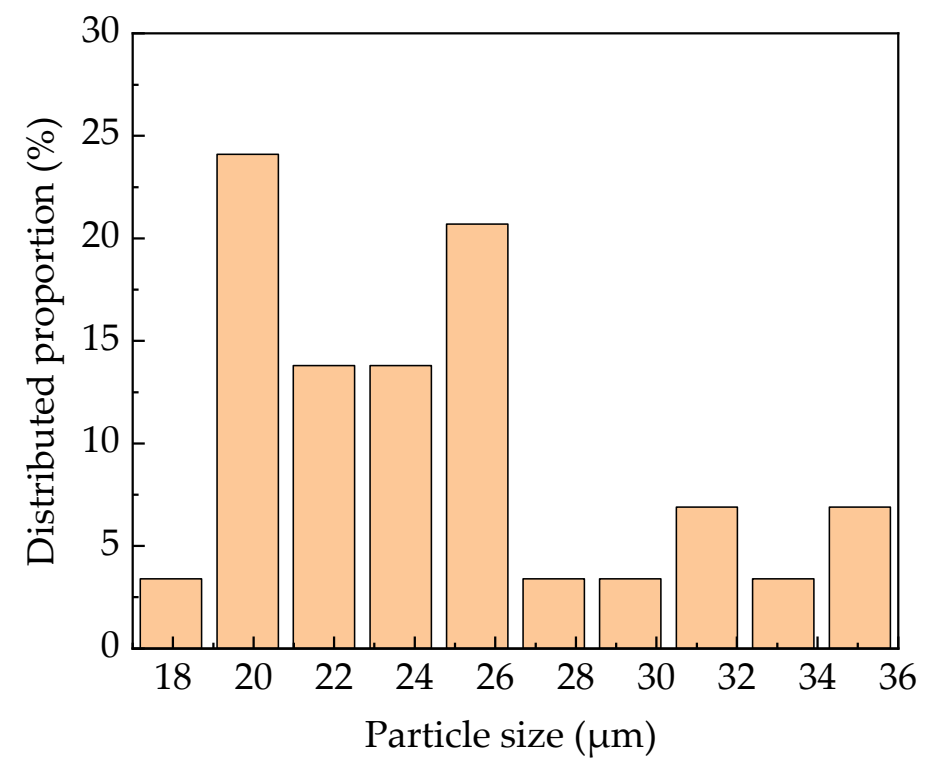

Figure 4. Typical particle size distribution of BC-m particles on fracture surface.

The addition of CS (Figure $3 b_{1}, b_{2}$ ) improved the interfacial bonding, whereby no obvious delamination could be observed compared to if $\mathrm{BC}-\mathrm{m}$ was added on its own. CS appears to facilitate BC-m dispersal and bonding with the PLA by acting as an interfacial adhesive.

\subsubsection{Thermal Properties}

To investigate the thermodynamic properties of PLA and its blends, differential scanning calorimetry (DSC) was carried out with heat flow curves shown in Figure 5. Key data, such as glass transition temperature $\left(\mathrm{T}_{\mathrm{g}}\right)$, cold crystallization temperature $\left(\mathrm{T}_{\mathrm{cc}}\right)$, crystallization enthalpy $\left(\Delta \mathrm{H}_{\mathrm{c}}\right)$, melting temperature $\left(\mathrm{T}_{\mathrm{m}}\right)$, and melting enthalpy $\left(\Delta \mathrm{H}_{\mathrm{m}}\right)$ are summarized in Table 2.

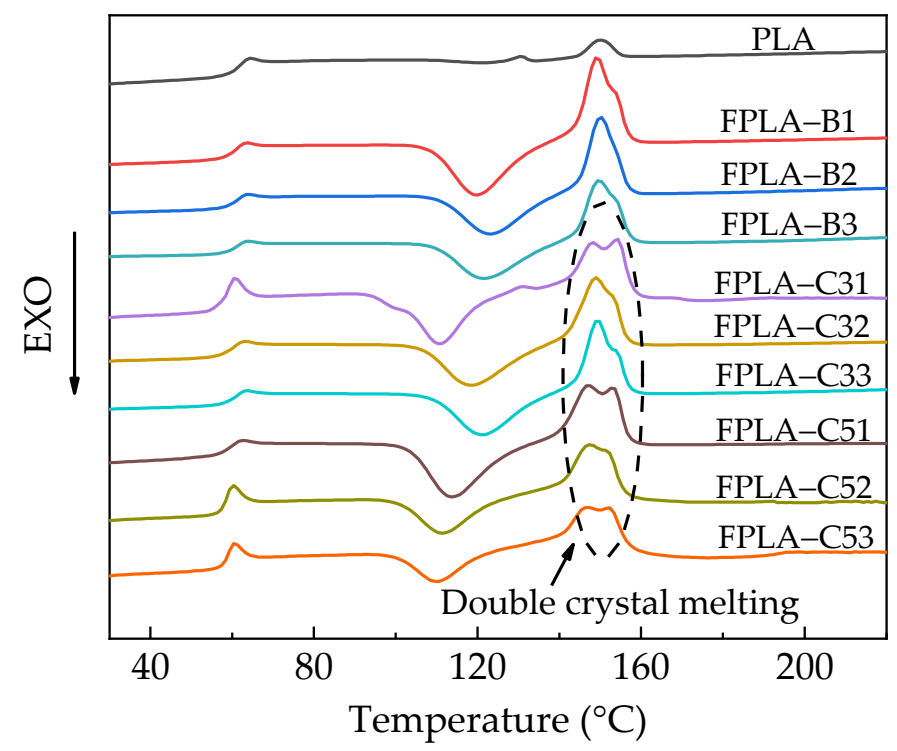

Figure 5. Heat flow curves of PLA and its blends. 
Table 2. DSC indices for PLA and FPLA composites.

\begin{tabular}{|c|c|c|c|c|c|c|c|}
\hline Sample & $T_{\mathrm{g}}\left({ }^{\circ} \mathrm{C}\right)$ & $T_{\mathrm{cc}}\left({ }^{\circ} \mathrm{C}\right)$ & $T_{\mathrm{m} 1}\left({ }^{\circ} \mathrm{C}\right)$ & $T_{\mathrm{m} 2}\left({ }^{\circ} \mathrm{C}\right)$ & $\Delta H_{\mathrm{c}}(\mathrm{J} / \mathrm{g})$ & $\Delta H_{\mathrm{m}}(\mathrm{J} / \mathrm{g})$ & $X \mathrm{c}(\%)$ \\
\hline PLA & 59.1 & 108.1 & 150.8 & - & 0.84 & 4.06 & 0.90 \\
\hline FPLA-B1 & 58.1 & 119.8 & 149.2 & - & 27.39 & 27.77 & 32.51 \\
\hline FPLA-B2 & 58.4 & 123.2 & 150.1 & - & 22.27 & 22.87 & 29.74 \\
\hline FPLA-B3 & 58.7 & 121.6 & 149.7 & - & 21.26 & 20.71 & 32.45 \\
\hline FPLA-C31 & 56.9 & 110.8 & 148.2 & 154.2 & 27.19 & 20.98 & 33.39 \\
\hline FPLA-C32 & 57.1 & 118.4 & 149.0 & - & 25.63 & 24.44 & 35.56 \\
\hline FPLA-C33 & 58.1 & 121.1 & 149.3 & - & 24.41 & 23.36 & 38.92 \\
\hline FPLA-C51 & 57.1 & 114.0 & 147.2 & 152.9 & 30.43 & 28.8 & 38.25 \\
\hline FPLA-C52 & 57.2 & 120.4 & 148.7 & 154.0 & 25.91 & 25.18 & 36.91 \\
\hline FPLA-C53 & 57.6 & 112.1 & 145.1 & 152.6 & 18.99 & 18.16 & 31.21 \\
\hline
\end{tabular}

From Table 2, the $\mathrm{T}_{\mathrm{g}}$ values decreased with the addition of $\mathrm{BC}$ and CS, likely caused by increased plasticization of the polymer [35,39]. At a particular level of BC-m (e.g., $20 \%$ as bold highlighted) $\mathrm{T}_{\mathrm{g}}$ values were minimally affected by CS level but $X_{\mathrm{c}}$ increased. Higher molecular mobility also means that more energy is needed to achieve crystallization while weakening the capacity for non-isothermal crystallization [30,39], leading to an increase in $T_{\mathrm{cc}}$ by $15.1^{\circ} \mathrm{C}$ at most. The nucleation by the fillers contributed greatly to the improvement of $X_{\mathrm{C}}$. With the increasing addition of BC and CS, the $X_{\mathrm{C}}$ of composites increased from $0.9 \%$ to over $29 \%$, the highest being FPLA-C 33 with $X_{C}=38.92 \%$, or 43 times that of pure PLA. The improvement of crystallization behavior also means that the thermal stability of the composite may be enhanced. Double melt crystallization peaks appeared with the addition of CS (Figure 5), especially at $3 \mathrm{wt} \%$, which may be attributed to incomplete cold crystallization at low temperatures resulting in the melting and recrystallization of $\alpha$ phase [17]. Equally, a slight decrease in $T_{\mathrm{m}}$ was observed with increase of CS content, as melting involves the same molecular movement condition [39]. The crystallization results suggest CS may play an important bridging role between BC-m and PLA by reducing the thickness and volume of the crystalline polymer interface [17].

\subsubsection{X-ray Diffraction Analysis}

X-ray diffraction was used to detect the differences in crystalline structure between PLA and FPLA composites (Figure 6). Only a broad diffraction peak for crystallinity in pure PLA at $16.7^{\circ}$ was recorded, assigned to the $\alpha$-phase crystallite $[40,41]$. Generally, the crystallization of pure PLA occurs too slowly to register any significant crystallinity, especially under the non-isothermal conditions encountered during extrusion and injection molding [41]. In contrast, a sharp crystallization peak at $16.7^{\circ}$ appeared in FPLA-CS, consistent with DSC results. With the addition of BC-m and chitosan in different ratios, several new diffraction peaks at $2 \theta=18.3^{\circ}, 20.9^{\circ}, 23.6^{\circ}, 24.5^{\circ}$, and $28.8^{\circ}$ appeared in the XRD curve. As reported previously, the peak at $2 \theta=20.9^{\circ}$ belongs to the graphitized structure of $\mathrm{BC}$ [17], and the $2 \theta=24.5^{\circ}$ and $28.8^{\circ}$ corresponds to the $\beta$-form crystal structure [42]. The peak values of all FPLA materials increased and became sharp at $16.7^{\circ}$, which indicates the crystallinity index of PLA increased [43]. New peaks at $2 \theta=18.3^{\circ}$ and $23.6^{\circ}$ suggest reorganization of the crystal structure [44].

\subsection{Mechanical Properties}

Figure 7 shows the tensile and flexural properties of the composites with different BC-m and CS addition levels, while the detailed data are listed in Table 3. 


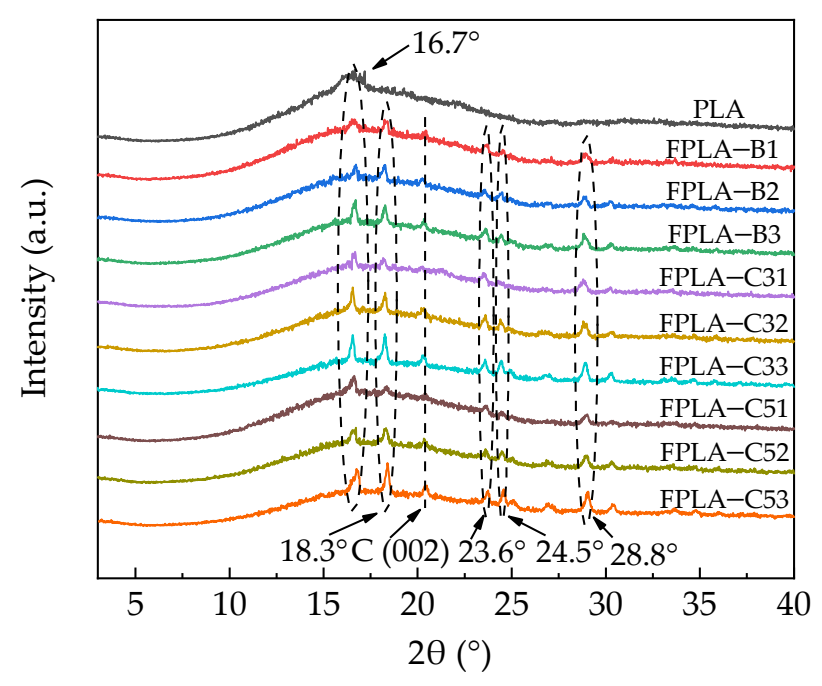

Figure 6. Diffraction patterns of PLA and FPLA composites.
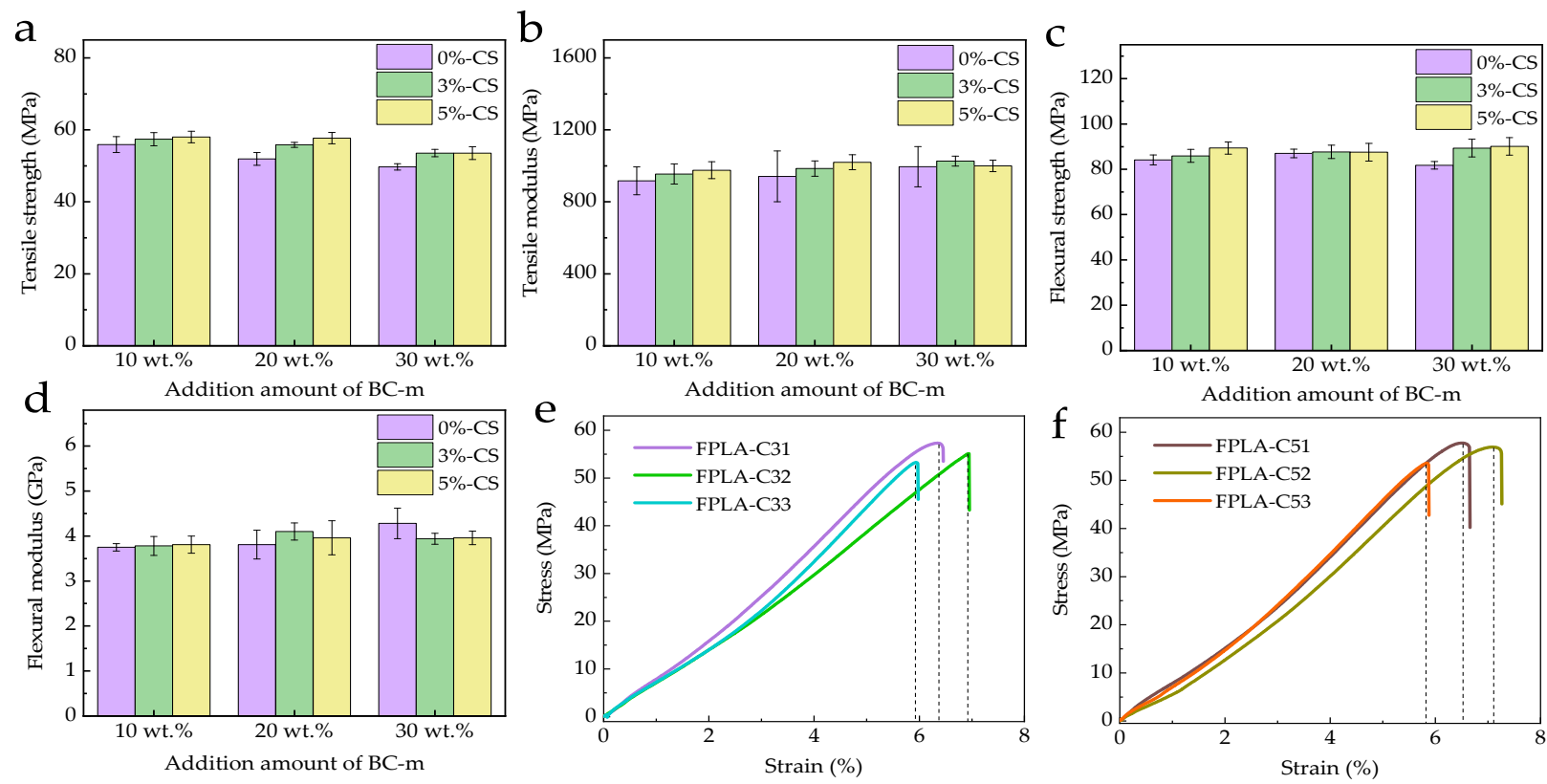

Figure 7. Average mechanical properties of FPLA-B and FPLA-C composites: (a) tensile strength, (b) tensile modulus, (c) flexural strength, and (d) flexural modulus; as well as typical tensile stress-strain curves of a selected sample: (e) FPLA-B composites and (f) FPLA-C composites.

Table 3. Mechanical properties of the FPLA-B and FPLA-C composites.

\begin{tabular}{ccccc}
\hline Sample & Tensile Strength (MPa) & Tensile Modulus (MPa) & Flexural Strength (MPa) & Flexural Modulus (GPa) \\
\hline a PLA & $\mathbf{5 8 . 1 2} \pm \mathbf{1 . 7 6}$ & $\mathbf{7 7 4 . 2 4} \pm \mathbf{3 3 . 4 3}$ & $\mathbf{9 5 . 7 6} \pm \mathbf{0 . 8 0}$ & $\mathbf{3 . 7 3} \pm \mathbf{0 . 1 7}$ \\
a FPLA-B1 & $55.91 \pm 2.23$ & $917.06 \pm 77.74$ & $84.15 \pm 2.18$ & $3.75 \pm 0.08$ \\
a FPLA-B2 & $\mathbf{5 1 . 9 4} \pm \mathbf{1 . 7 7}$ & $\mathbf{9 4 1 . 1 5} \pm \mathbf{1 4 1 . 3 3}$ & $\mathbf{8 7 . 0 1} \pm \mathbf{1 . 9 0}$ & $\mathbf{3 . 8 1} \pm \mathbf{0 . 3 2}$ \\
a FPLA-B3 & $49.71 \pm 0.88$ & $995.70 \pm 112.20$ & $81.77 \pm 1.65$ & $4.28 \pm 0.34$ \\
FPLA-C31 & $57.40 \pm 1.83$ & $955.02 \pm 56.03$ & $85.95 \pm 2.84$ & $3.78 \pm 0.21$ \\
FPLA-C32 & $\mathbf{5 5 . 8 4} \pm \mathbf{0 . 6 7}$ & $\mathbf{9 8 5 . 1 6} \pm \mathbf{4 2 . 7 5}$ & $\mathbf{8 7 . 7 0} \pm \mathbf{2 . 9 4}$ & $\mathbf{4 . 1 0} \pm \mathbf{0 . 1 9}$ \\
FPLA-C33 & $53.56 \pm 1.02$ & $1026.41 \pm 27.41$ & $89.37 \pm 3.94$ & $3.94 \pm 0.12$ \\
FPLA-C51 & $58.00 \pm 1.61$ & $976.00 \pm 47.30$ & $89.40 \pm 2.68$ & $3.81 \pm 0.19$ \\
FPLA-C52 & $\mathbf{5 7 . 7 1} \pm \mathbf{1 . 5 7}$ & $\mathbf{1 0 2 0 . 4 3} \pm \mathbf{4 1 . 1 4}$ & $\mathbf{8 7 . 5 5} \pm \mathbf{3 . 9 0}$ & $\mathbf{3 . 9 6} \pm \mathbf{0 . 3 8}$ \\
FPLA-C53 & $53.54 \pm 1.77$ & $999.86 \pm 32.44$ & $90.12 \pm 3.87$ & $3.95 \pm 0.14$ \\
\hline
\end{tabular}

Notes: ${ }^{a}$ Reprinted with permission from ref [18]. Copyright 2021 American Chemical Society. Copyright Liang Zhang, Weisheng Chai, Wenzhu Li, Kate Semple, Ningning Yin, Wenbiao Zhang, Chunping Dai. 
As noted in previous work [18], the tensile strength of FPLA-B composites decreases with increased BC-m addition, with a $11.09 \%$ decrease at $30 \mathrm{wt} . \%$ BC-m. Adding CS significantly improved the tensile properties as seen in Figure $7 \mathrm{a}, \mathrm{b}$ and in Table 3 bold values of FPLA-B composites. CS at 5 wt.\% produced the largest increases: $11.11 \%$ in tensile strength and $8.42 \%$ in tensile modulus. Flexural properties were less changed by CS addition (Figure 7c,d, Table 3). Typical stress-strain curves for CS-added FPLA-Cs are shown in Figure 7e,f. Note the elongation at break is more sensitive to the compatibilization effect in multicomponent blends compared with other mechanical properties [45]. Adding $20 \mathrm{wt} . \% \mathrm{BC}-\mathrm{m}$ and $3 \mathrm{wt} . \%$ or $5 \mathrm{wt} . \%$ CS produced a more ductile composite with elongation at the break reaching $6.94 \%$ and $7.08 \%$, respectively, which is $2.20 \%$ and $8.59 \%$ higher than that of 10\% BC-m added with same content of CS.

CS particles with medium viscosity are dispersed in advance forming a flexible membrane locally under the action of pressure and temperature and effectively promoting the interfacial bonding between the filler and matrix, as indicated through observation of fracture morphology and higher composite strength and the modulus results. The enhancement is limited to low doses of CS as it is strongly hydrophilic due to - $\mathrm{OH}$ and $-\mathrm{NH}_{2}$ groups along the chain [46], whereas PLA is strongly hydrophobic [47,48]. As CS loading increases, the extent of interfacial zones with different affinities leads to a weakening in interfacial adhesion and interaction [28].

\subsection{Thermal Degradation Behavior \\ 3.3.1. $\mathrm{TG}$ in $\mathrm{N}_{2}$}

Selected TG and DTG curves of PLA, PLA/20BC-m, PLA/20BC-m/3CS, and PLA/20BC$\mathrm{m} / 5 \mathrm{CS}$ in nitrogen atmosphere are shown in Figure 8 , and corresponding data for all mixes are shown in Table 4. The onset degradation temperature of samples is defined as the temperature at $5 \%$ weight loss $\left(T_{-5 \%}\right)$, and $T_{\max }$. is the temperature at the maximum rate of rate of mass loss.
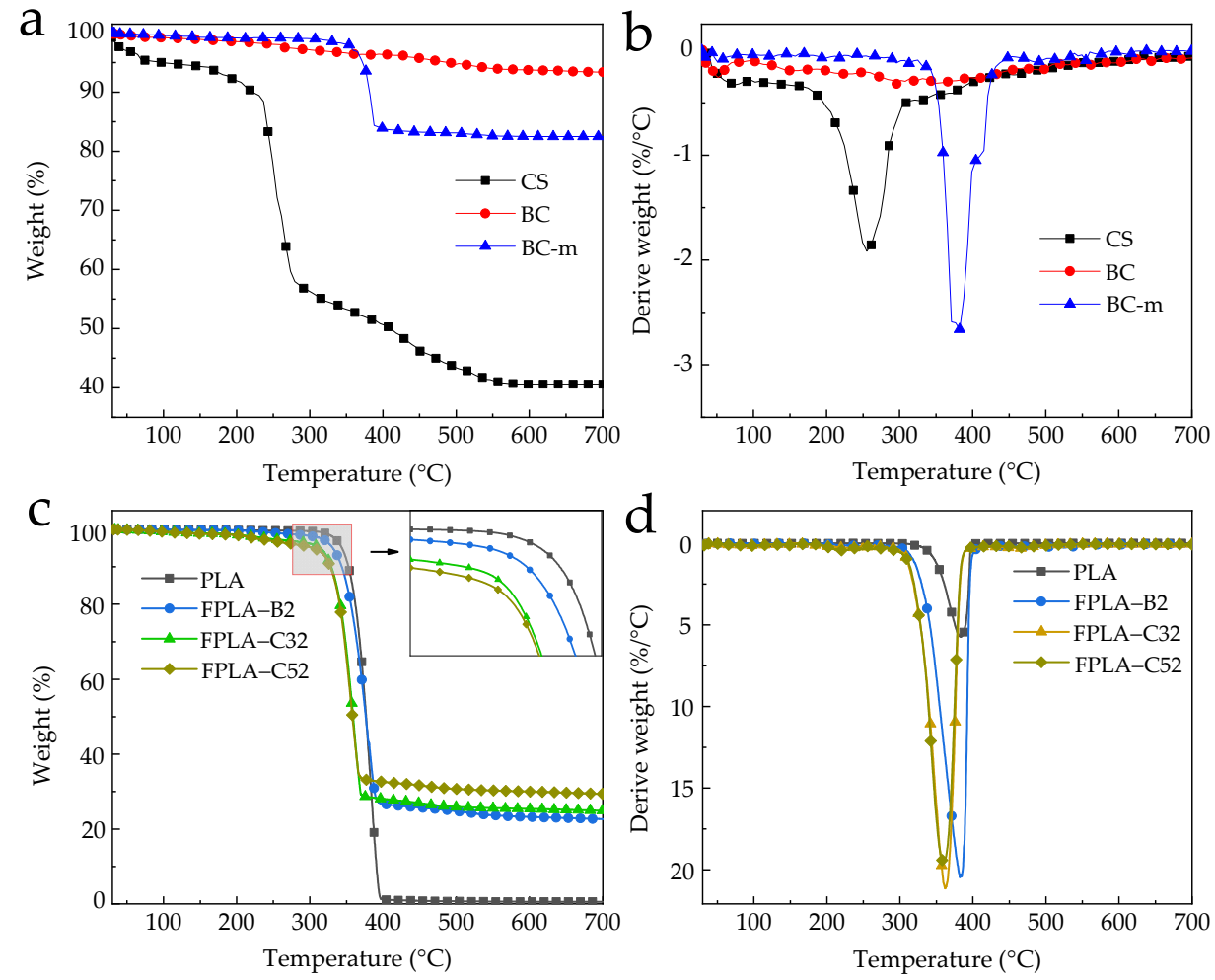

Figure 8. Typical TGA $(\mathbf{a}, \mathbf{c})$ and DTG $(\mathbf{b}, \mathbf{d})$ curves of CS, BC; BC-m, PLA, and FPLA composites in $\mathrm{N}_{2}$. 
Table 4. TGA data of PLA and FPLA composites in $\mathrm{N}_{2}$.

\begin{tabular}{|c|c|c|c|}
\hline \multirow{2}{*}{ Samples } & \multirow{2}{*}{$\mathrm{T}_{-5 \%}\left({ }^{\circ} \mathrm{C}\right)$} & \multirow{2}{*}{$\mathrm{R}_{\text {peak }} / \mathrm{T}_{\max }\left(\% \cdot \min ^{-1} /{ }^{\circ} \mathrm{C}\right)$} & \multirow{2}{*}{$\begin{array}{c}\text { Residue Mass (\%) } \\
700\left({ }^{\circ} \mathrm{C}\right)\end{array}$} \\
\hline & & & \\
\hline BC & 484 & $0.32 / 295$ & 93.39 \\
\hline BC-m & 373 & $2.66 / 382$ & 82.47 \\
\hline CS & 103 & $1.92 / 255$ & 40.60 \\
\hline PLA & 343 & $5.72 / 382$ & 0.60 \\
\hline a FPLA-B1 & 334 & $25.33 / 385$ & 8.64 \\
\hline a FPLA-B2 & 331 & $20.94 / 383$ & 21.81 \\
\hline a FPLA-B3 & 331 & $19.52 / 380$ & 29.83 \\
\hline FPLA-C31 & 316 & $22.24 / 365$ & 8.97 \\
\hline FPLA-C32 & 314 & $21.14 / 362$ & 24.92 \\
\hline FPLA-C 33 & 311 & $18.81 / 359$ & 29.56 \\
\hline FPLA-C51 & 312 & $23.46 / 365$ & 9.64 \\
\hline FPLA-C52 & 306 & $19.55 / 360$ & 29.42 \\
\hline FPLA-C53 & 304 & $18.65 / 356$ & 32.74 \\
\hline
\end{tabular}

Notes: ${ }^{a}$ Reprinted with permission from ref [18]. Copyright 2021 American Chemical Society. Copyright Liang Zhang, Weisheng Chai, Wenzhu Li, Kate Semple, Ningning Yin, Wenbiao Zhang, Chunping Dai.

Typical TG and DTG spectra for the constituents CS, BC, and BC-m under nitrogen $\left(\mathrm{N}_{2}\right)$ atmosphere are shown in Figure 8a,b. CS started to thermally decompose at $103^{\circ} \mathrm{C}$. $\mathrm{R}_{\text {peak }}$ occurred at $255^{\circ} \mathrm{C}$ and the final carbon residue at $700{ }^{\circ} \mathrm{C}$ was $40.60 \%$. In contrast, $\mathrm{BC}$ showed excellent thermal stability with almost no significant mass loss during pyrolysis. $R_{\text {peak }}$ was $0.32 \%$ at $295{ }^{\circ} \mathrm{C}$ and the final carbon residue was $93.39 \%$. BC-m underwent rapid mass loss of its graft products at $382{ }^{\circ} \mathrm{C}$ and with a final carbon residue of $82.47 \%$. The grafted phosphorous and nitrogen compounds on $\mathrm{BC}-\mathrm{m}$ reduced the relative mass of pure $\mathrm{BC}$ in the filler by $10.94 \%$.

Data for FPLA composites are shown in Figure 8c,d and Table 3, with notable contrasts for $20 \%$ BC-m with or without CS in bold highlight. FPLA composites were characterized by one $T_{\max }$ and $T_{-5} \%$ values were lower than for pure PLA, especially with CS addition. This is related to the early thermal decomposition of BC-m graft products in keeping with thermal degradation of IFRs $[49,50]$ and contributing to its flame retardancy. The residue mass (RM) values of all FPLA were higher than pure PLA $(0.60 \%)$ at $700{ }^{\circ} \mathrm{C}$. The RM values of CS-added materials at the same level of BC-m content were higher again, suggesting a cooperative effect. This is evidenced by the RM being higher than the theoretical value for BC-m composites above $20 \%$ BC-m. The RM of FPLA-C52 (20\%BC-m+5\%CS) for example, was $29.42 \%$, i.e., $55.1 \%$ higher than its theoretical value of $18.97 \%$. BC-m decomposition produces phosphoric acid (PA) which accelerates the degradation of PLA in cooperation with higher content of CS further reducing $T_{-5} \%$ and earlier char formation, potentially providing enhanced combustion resistance $[21,33,34]$. Note the increase in RM is limited at low (3\%) CS addition level.

\subsubsection{TG in Air}

TG results in air are given in Figure 9 and Table 5.

Compared with nitrogen atmosphere, $\mathrm{T}_{-5 \%}$ values increased that with $5 \mathrm{wt} . \% \mathrm{CS}$ and $\mathrm{T}_{-5 \%}$ values of FPLA-C51, FPLA-C52, and FPLA-C53 increased by $12{ }^{\circ} \mathrm{C}, 7^{\circ} \mathrm{C}$, and $3{ }^{\circ} \mathrm{C}$, respectively. All values for $R_{\text {peak }}$ of the FPLA composites rose as well, while corresponding $\mathrm{T}_{\max }$ values decreased. Oxygen promotes the pyrolysis process of PLA by oxidizing the molecular chains [10], intensifying the pyrolysis reaction and promoting the formation of the carbonized char layer, resulting in earlier inhibition of mass loss. TGA results in air still indicate adding $\mathrm{BC}-\mathrm{m}$ and $\mathrm{CS}$ as a cooperative system is effective in promoting the early formation of char residue but note here the much smaller difference between CS levels when added to a base level of 20\%BC-m (bold in Table 5). 

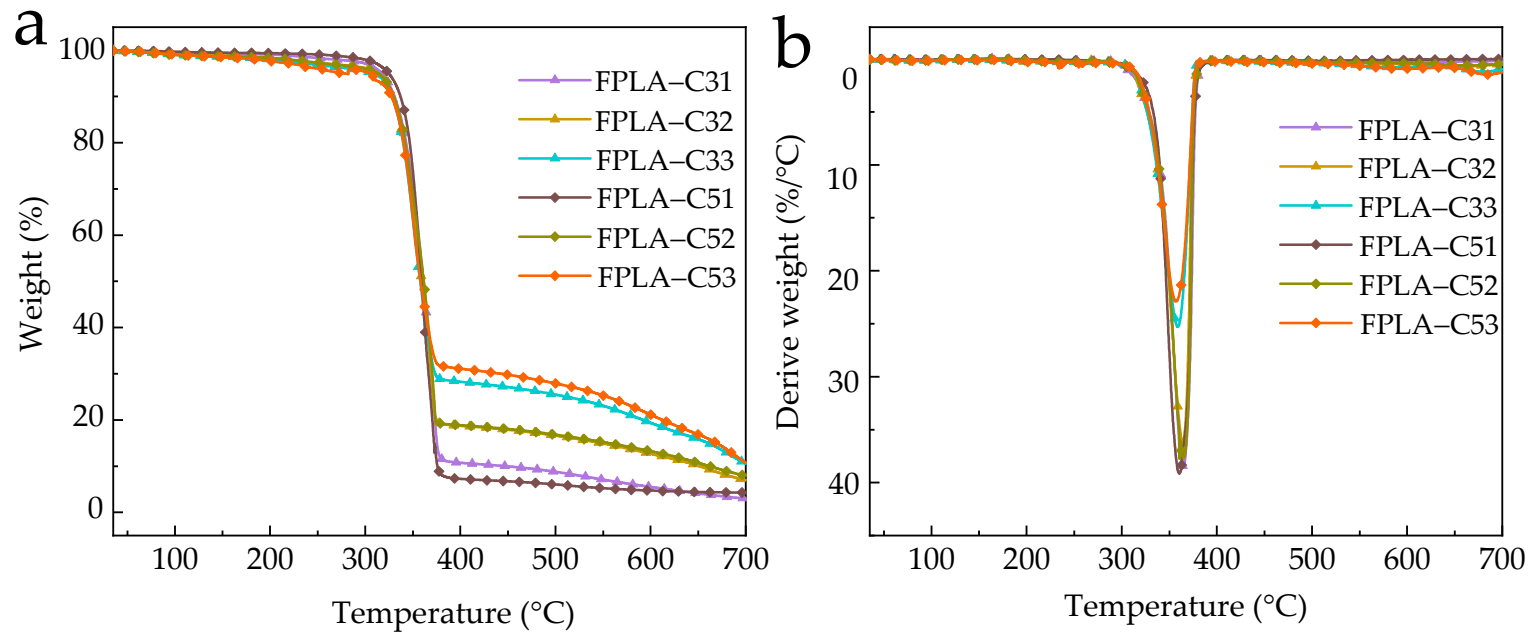

Figure 9. TGA (a) and DTG (b) curves of FPLA composites in air.

Table 5. TGA data of FPLA composites under air condition.

\begin{tabular}{cccc}
\hline Samples & $\mathbf{T}_{-5 \%}\left({ }^{\circ} \mathbf{C}\right)$ & $\mathbf{R}_{\text {peak }} / \mathbf{T}_{\max }\left(\boldsymbol{\%} \cdot \mathbf{m i n}^{-1} /{ }^{\circ} \mathbf{C}\right)$ & Residue Mass (\%) \\
\cline { 4 - 4 } & 317 & $38.48 / 363$ & $\mathbf{7 0 0}\left({ }^{\circ} \mathbf{C}\right)$ \\
\hline FPLA-C31 & 314 & $36.57 / 362$ & 3.01 \\
FPLA-C32 & 311 & $25.30 / 358$ & $\mathbf{6 . 9 9}$ \\
FPLA-C33 & 324 & $39.14 / 360$ & 10.48 \\
FPLA-C51 & 313 & $37.76 / 360$ & 4.30 \\
FPLA-C52 & 307 & $22.90 / 355$ & 8.10 \\
\hline
\end{tabular}

\subsection{Combustion Characterization}

\subsubsection{LOI and UL-94}

Flammability indices for PLA and FPLA composites (LOI and UL-94 tests) are summarized in Table 6 with contrasts for CS level with 20\%BC-m in bold. Images of PLA and FPLA-C composites after the LOI tests are shown in Figure 10.

Table 6. LOI and UL-94 results of PLA and FPLA composites.

\begin{tabular}{|c|c|c|c|c|c|}
\hline \multirow{2}{*}{ Samples } & \multirow{2}{*}{$\mathrm{LOI} \pm 0.2(\mathrm{vol} \%)$} & \multicolumn{3}{|c|}{ UL-94 } & \multirow{2}{*}{$\mathrm{Ce}$} \\
\hline & & ${ }^{a} t_{1}(s) / t_{2}(s)$ & Dripping & Rating & \\
\hline PLA & 20.7 & $\mathrm{~b}$ TB & Yes & ${ }^{\mathrm{c}} \mathrm{NR}$ & - \\
\hline FPLA-C3 & 21.5 & $\mathrm{~TB}$ & Yes & NR & - \\
\hline FPLA-C5 & 21.7 & $\mathrm{~TB}$ & Yes & NR & - \\
\hline d FPLA-B1 & 28.0 & $5.6 / 2.3$ & Yes & $\mathrm{V}-2$ & - \\
\hline d FPLA-B2 & 29.2 & $2.1 / 1.1$ & No & V-0 & - \\
\hline d FPLA-B3 & 32.1 & $1.2 / 1.4$ & No & $\mathrm{V}-0$ & - \\
\hline FPLA-C 31 & 29.0 & $4.7 / 2.0$ & No & V-1 & 1.02 \\
\hline FPLA-C32 & 31.3 & 1.9/1.1 & No & V-0 & 1.14 \\
\hline FPLA-C33 & 33.0 & $1.2 / 1.3$ & No & $\mathrm{V}-0$ & 1.01 \\
\hline FPLA-C51 & 29.2 & $4.6 / 2.1$ & No & V-1 & 1.02 \\
\hline FPLA-C52 & 32.4 & $1.8 / 1.2$ & No & $\mathrm{V}-\mathbf{0}$ & 1.23 \\
\hline FPLA-C53 & 33.6 & $1.0 / 1.0$ & No & $\mathrm{V}-0$ & 1.04 \\
\hline
\end{tabular}

a average combustion times after the first and second applications of the flame; ${ }^{\mathrm{b}} \mathrm{TB}=$ totally burnt down to clamp;

${ }^{c}$ No rating; ${ }^{d}$ Reprinted with permission from ref [18]. Copyright 2021 American Chemical Society. Copyright Liang Zhang, Weisheng Chai, Wenzhu Li, Kate Semple, Ningning Yin, Wenbiao Zhang, Chunping Dai. 

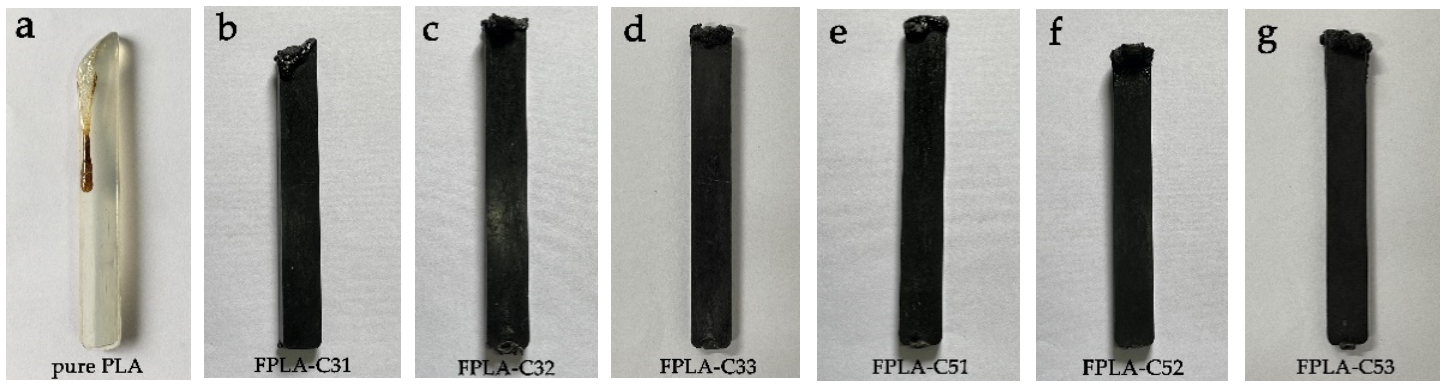

Figure 10. Digital images of PLA and FPLA composites after LOI tests: (a) pure PLA; (b) 3CS/10BC-m/87PLA; (c) 3CS/20BCm/77PLA; (d) 3CS/30BC-m/67PLA; (e) 5CS/10BC-m/85PLA; (f) 5CS/20BC-m/75PLA; (g) 5CS/30BC-m/65PLA.

Pure PLA burns very easily and exhibited obvious melt dripping (Figure 10a) with a LOI of $20.7 \mathrm{vol} \%$. CS has little flame retardancy if added alone; LOI values were increased slightly to $21.5 \mathrm{vol} \%$ and $21.7 \mathrm{vol} \%$, respectively. Our previous findings [18] showed that with 20 and $30 \mathrm{wt} . \%$ addition of BC-m, LOI increased to $29.2 \mathrm{vol} \%$ and $32.1 \mathrm{vol} \%$, respectively, and melt dripping was completely suppressed, achieving a UL-94 V-0 rating. However, $10 \mathrm{wt. \%}$ BC-m was insufficient to prevent melting [18]. With co- addition of CS, the expansion phenomenon at the burning tip became more obvious, as seen in Figure $10 \mathrm{~d}, \mathrm{~g}$. CS addition further increased the LOI of $20 \%$ BC-m from $29.2 \% \mathrm{vol} \%$ to $31.3 \mathrm{vol} \%$ and $32.4 \mathrm{vol} \%$ for the $3 \%$ and $5 \%$ CS addition, respectively.

The possible cooperative effect of adding BC-m and CS in combination was further explored using the Lewin and Weil concept of cooperative effectiveness (Ce) [51], calculated as follows [52]:

$$
\left.\mathrm{Ce}=\left\{\left(\mathrm{F}_{\mathrm{p}}\right)_{[\mathrm{fr}+\mathrm{s}]}-\left(\mathrm{F}_{\mathrm{p}}\right)_{\mathrm{P}}\right\} /\left\{\left(\mathrm{F}_{\mathrm{p}}\right)_{\mathrm{fr}}-\mathrm{F}_{\mathrm{p}}\right)_{\mathrm{P}}\right)+\left(\left(\mathrm{F}_{\mathrm{p}}\right)_{\mathrm{s}}-\left(\mathrm{F}_{\mathrm{p}}\right)_{\mathrm{P}}\right\}
$$

where $\left(F_{p}\right)_{P}$ is the flame-retardant property of the polymer alone, $\left(F_{p}\right)_{f r}$ is the polymer containing BC-m, $\left(\mathrm{F}_{\mathrm{p}}\right)_{\mathrm{s}}$ is the polymer with $\mathrm{CS}$, and $\left(\mathrm{F}_{\mathrm{p}}\right)_{[\mathrm{fr}+\mathrm{s}]}$ is the polymer with cooperative filler system $(\mathrm{BC}-\mathrm{m}+\mathrm{CS})$. Cooperative behavior of the additives is considered to occur with the combination of BC-m and CS if $\mathrm{Ce}>1$. Since the LOI values are usually used to evaluate combustion intensity and directly correspond with UL-94 and cone calorimetry indices, LOI values were used for $F_{p}$ in Equation (2) [16,52]. Ce values were above 1 for $\mathrm{BC}-\mathrm{m}+\mathrm{CS}$ composites (Table 6) suggesting a cooperative effect. Overall, $20 \mathrm{wt} . \% \mathrm{BC}-\mathrm{m}$ with $5 \%$ CS was the most effective, in accord with the TGA results under $\mathrm{N}_{2}$ atmosphere.

\subsubsection{Cone Calorimeter (CONE) Results}

The appearance of char residues aids interpretation of CONE data [53]. Examples of chars from PLA and FPLA-C composites (at baseline 20\% BC-m addition) after CONE tests are shown in Figure 11. With CS addition, the 'puffiness' of the char increased, as seen in Figure $11 c_{2}, d_{2}$. Key parameters include the heat release rate (HRR), total heat release (THR), total smoke release (TSR), residue mass (RM), and average effective heat of combustion (aEHC); with data for all samples given in Table 7. Selected curves for PLA, PLA $+20 \%$ BC-m and this baseline with CS addition are shown for easier visual comparison in Figure 12.
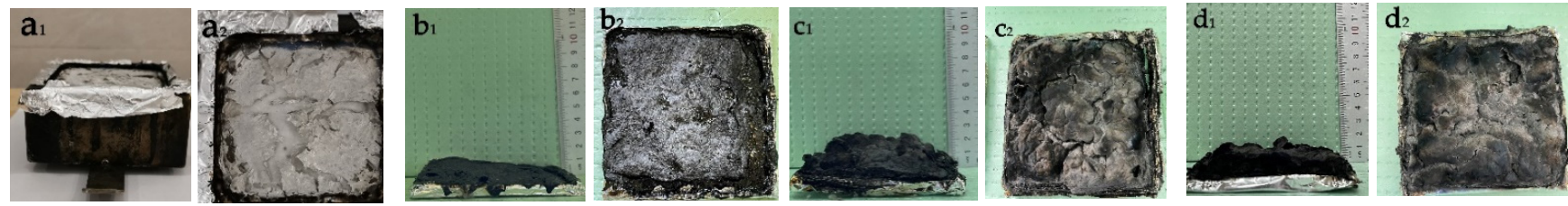

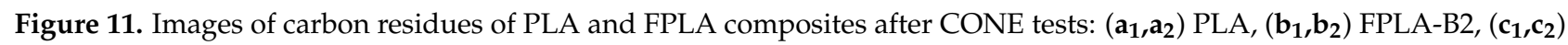
FPLA-C32, and $\left(\mathbf{d}_{\mathbf{1}}, \mathbf{d}_{\mathbf{2}}\right)$ FPLA-C52. 
Table 7. ${ }^{\text {a }}$ Cone calorimeter results for each sample at $35 \mathrm{~kW} / \mathrm{m}^{2}$.

\begin{tabular}{|c|c|c|c|c|c|c|}
\hline Samples & TTI (s) & pHRR $\left(\mathrm{kW} / \mathrm{m}^{2}\right)$ & THR $\left(\mathrm{MJ} / \mathrm{m}^{2}\right)$ & $\mathrm{pMLR}(\mathrm{g} / \mathrm{s})$ & aEHC (MJ/kg) & RM (\%) \\
\hline PLA & 56 & 435.58 & 86.06 & 0.60 & 16.37 & 2.29 \\
\hline b FPLA-B1 & 34 & 418.11 & 68.64 & 0.51 & 16.15 & 6.45 \\
\hline b FPLA-B2 & 33 & 201.02 & 53.48 & 0.48 & 15.08 & 18.99 \\
\hline b FPLA-B3 & 31 & 181.61 & 41.10 & 0.35 & 14.52 & 47.71 \\
\hline FPLA-C31 & 37 & 216.33 & 54.19 & 0.67 & 12.28 & 8.36 \\
\hline FPLA-C32 & 35 & 146.97 & 37.17 & 0.61 & 12.04 & 23.17 \\
\hline FPLA-C33 & 34 & 123.38 & 29.00 & 0.37 & 11.01 & 35.99 \\
\hline FPLA-C51 & 36 & 268.56 & 42.04 & 0.52 & 12.68 & 8.22 \\
\hline FPLA-C52 & 37 & 156.85 & 38.79 & 0.74 & 11.67 & 26.26 \\
\hline FPLA-C53 & 34 & 125.49 & 25.65 & 0.53 & 10.66 & 38.18 \\
\hline
\end{tabular}

Notes: ${ }^{\text {a }}$ TTI, time to ignition, $\pm 2 \mathrm{~s}$; pHRR, peak heat release rate, $\pm 15 \mathrm{~kW} / \mathrm{m}^{2} ; \mathrm{pMLR}$, peak mass loss rate, $\pm 0.05 \mathrm{~g} / \mathrm{s}$; aEHC, average effective heat of combustion within $180 \mathrm{~s}, \pm 2 \mathrm{MJ} / \mathrm{kg} ;{ }^{\mathrm{b}}$ Reprinted with permission from ref [18]. Copyright 2021 American Chemical Society. Copyright Liang Zhang, Weisheng Chai, Wenzhu Li, Kate Semple, Ningning Yin, Wenbiao Zhang, Chunping Dai.
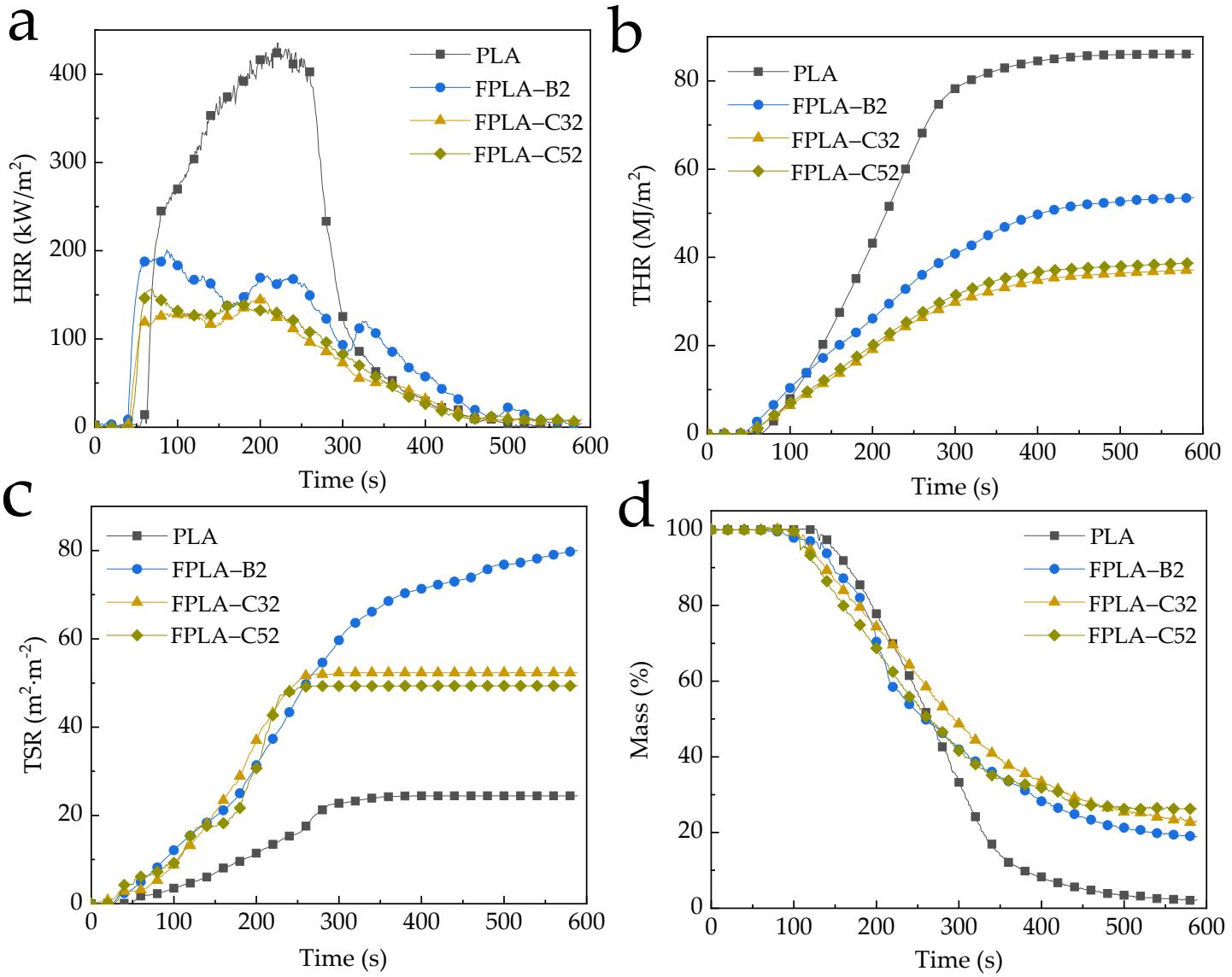

Figure 12. Typical CONE test results of PLA and FPLA composites: (a) HRR, (b) THR, (c) TSR, and (d) mass.

HRR curves of selected samples are shown in Figure 12a, which a main factor indicating fire spread risk [54]. Contrasted CONE indices for PLA, PLA+20\%BC-m and this baseline plus 3 or $5 \%$ CS addition are in bold in Table 7 . The heat release of all specimens mainly occurred between 100 and $300 \mathrm{~s}$. Peak heat release rate (pHRR) of pure PLA reached $435.58 \mathrm{~kW} / \mathrm{m}^{2}$ and was reduced by just $4.01 \%$ when $10 \mathrm{wt} . \%$ BC-m was added [18]. Even at low BC-m addition, CS can be effective. From Table 7, co-adding $3 \mathrm{wt}$ \% CS to this mix reduced pHRR to $216.33 \mathrm{~kW} / \mathrm{m}^{2}$, a decrease of $50.34 \%$. Adding $5 \mathrm{wt} . \% \mathrm{CS}$ did not further limit heat release; in fact, for PLA/20\%BC-m, adding $5 \mathrm{wt}$ \% CS increased pHRR to $156.45 \mathrm{~kW} / \mathrm{m}^{2}$ from $146.97 \mathrm{~kW} / \mathrm{m}^{2}$ for $3 \%$ CS. CS addition significantly reduced THR and aEHC indices compared with PLA and PLA/20\%BC-m (Figure 12b). 
From Table 7 and Figure 12a,b pHRR and THR for the baseline PLA+20\%BC-m were further reduced by CS addition, particularly $3 \%$. For example pHRR was reduced by almost $27 \%$ by adding $3 \% \mathrm{CS}$ to the baseline PLA+20\% BC-m. Note from Figure $12 \mathrm{c}$ CS addition curtailed TSR after about 250s compared with adding BC-m on its own. It seems likely that the cooperation of CS and BC-m accelerates the development of expanded char and greater amounts of non-flammable gases with heating, producing a greater peak mass loss rate (pMLR) and TSR. The char barrier is effective and works by blocking heat and oxygen, as shown in the reductions in pHRR and THR [55] when CS was added to all levels of $\mathrm{BC}-\mathrm{m}$ addition.

\subsection{Residue Analysis}

\subsubsection{Morphology of Residue Surfaces and Inner Layers}

The char residue on the outer and inner surface of FPLA-B and FPLA-C composites after CONE tests was analyzed by SEM, and the results are shown in Figure 13. When CS was not added, there was a dense char on the surface of the residue but with cavities (Figure $13 \mathrm{a}_{1}$ ), allowing heat and oxygen through. Adding CS helped produce a more continuous layer of char, as reflecting in the improved CONE test indices. Images of the internal char layer revealed changed morphology of the char layer. From previous work [18], PLA/BC-m, especially at 30\% addition formed a distinct filled-pore structure shown in Figure $13 \mathrm{a}_{2}$. With CS addition the char was denser and well consolidated without bubbles, as shown in Figure $13 b_{2}, c_{2}$. An enhanced barrier role appears to be achieved through the cooperative effect of CS and incombustible gases and acids produced by the thermal decomposition of BC-m. Adding BC-m to PLA causes pyrophosphate products to fill the pores in the char produced by gases generated during the thermal degradation of BC-m graft products [18]. As combustion progresses, flame suppression transitions to the condensed phase protective mechanism.
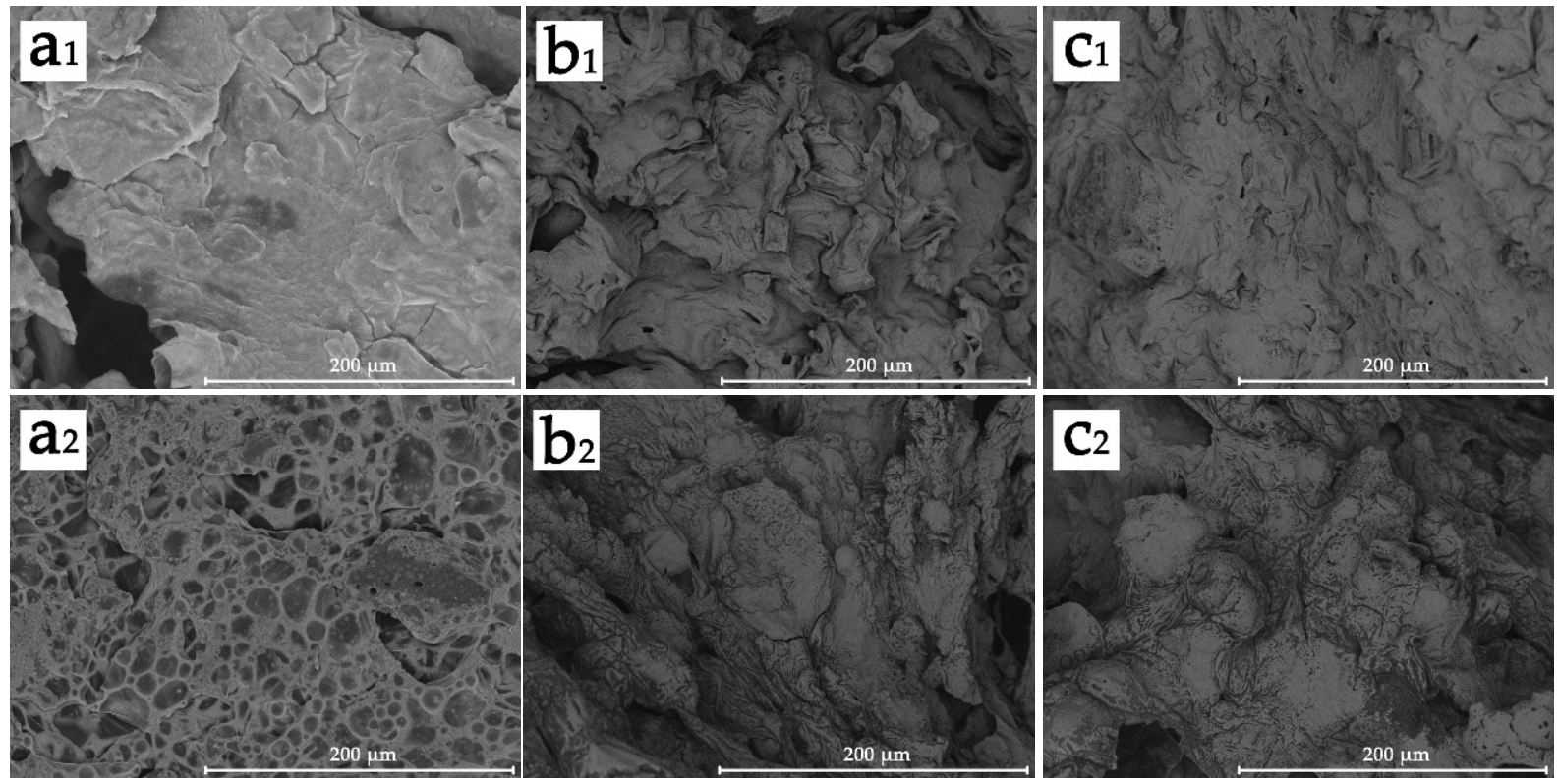

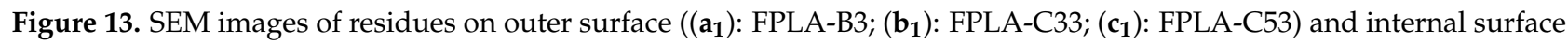
$\left(\left(\mathbf{a}_{2}\right)\right.$ : FPLA-B3; $\left(\mathbf{b}_{2}\right)$ : FPLA-C33; $\left(\mathbf{c}_{2}\right)$ : FPLA-C53) from FPLA composites after cone tests. 


\subsubsection{Structure and Composition}

In order to elucidate differences in the char residue structure, the residues of PLA, FPLA-B3, FPLA-C33, and FPLA-C53 (maximum level of BC-m addition) were analyzed by FTIR, with results shown in Figure 14a. The typical characteristic peaks of PLA at $1630 \mathrm{~cm}^{-1}, 1760 \mathrm{~cm}^{-1}, 2846 \mathrm{~cm}^{-1}$, and $2920 \mathrm{~cm}^{-1}$ were identified, corresponding to $C=C$, $\mathrm{C}=\mathrm{O}$, and symmetrical and asymmetrical stretching of $-\mathrm{CH}_{2}-$ groups, respectively [56,57]. Adding BC-m and CS together produced significantly different spectra compared with PLA, with new absorption peaks at $996 \mathrm{~cm}^{-1}, 1080 \mathrm{~cm}^{-1}$, and $1168 \mathrm{~cm}^{-1}$ in FPLA-C33 and FPLAC53. These correspond to the stretching vibration of $\mathrm{P}=\mathrm{O}, \mathrm{P}-\mathrm{O}-\mathrm{C}$, and $\mathrm{P}-\mathrm{O}-\mathrm{P}[56,58]$ from the graft products on $\mathrm{BC}-\mathrm{m}$, indicating pyrophosphates that contribute to the formation of char residue [56].
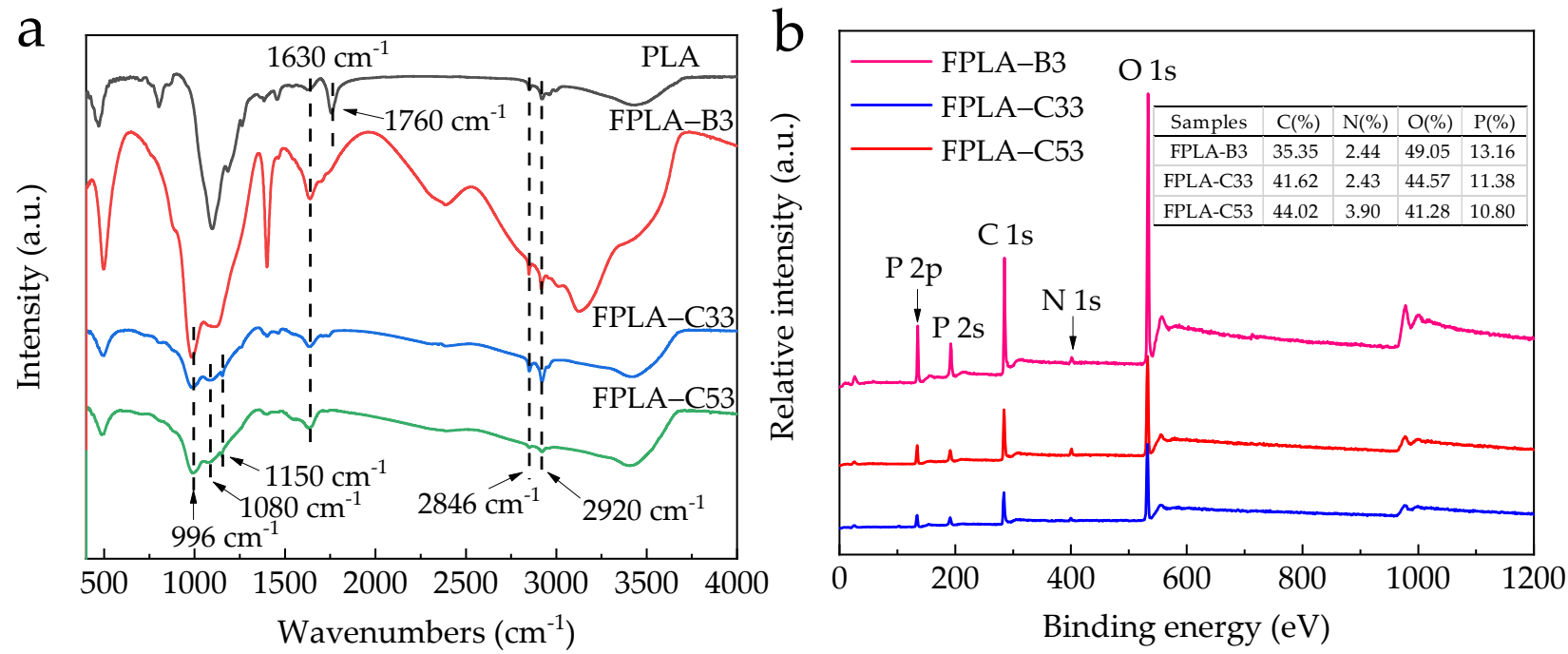

Figure 14. (a) FTIR curves and (b) XPS spectra of the residue char for PLA, FPLA-B3, FPLA-C33, and FPLA-53.

To further investigate the chemical element components of the char residues after CONE testing, XPS was performed with the corresponding spectra shown in Figure 14b. C and $\mathrm{O}$ contents exceeded $35 \%$, making up the majority of the residue. $\mathrm{C}$ content increased with greater CS addition.

Specific spectra are shown in Figure 15 for elements on the surface of the carbon residue of FPLA-C53. From Figure 15a, the binding energy (BE) at $284.1 \mathrm{eV}$ and $286.8 \mathrm{eV}$ for $\mathrm{C}$ 1s peaks was assigned to $\mathrm{C}-\mathrm{C}$ or $\mathrm{C}=\mathrm{C}$ groups in aliphatic and aromatic fragments, or $\mathrm{C}-\mathrm{O}$ in $\mathrm{P}-\mathrm{O}-\mathrm{C}$ groups, respectively, while the signal at $533.1 \mathrm{eV}$ in Figure $15 \mathrm{~b}$ corresponds to $-\mathrm{O}-$ in $\mathrm{P}-\mathrm{O}-\mathrm{C}$ [59]. The peak at $134.7 \mathrm{eV}$ of the $\mathrm{P} 2 \mathrm{p}$ spectra in Figure $15 \mathrm{c}$ and $401.2 \mathrm{eV}$ of $\mathrm{N}$ 1s spectra in Figure $15 \mathrm{~d}$ correspond to the $\mathrm{P}-\mathrm{O}-\mathrm{P}$ bond and the $\mathrm{C}-\mathrm{N}$ or $\mathrm{C}=\mathrm{N}$ in the triazine structures, respectively $[16,59,60]$. Theoretically, the content of elemental $\mathrm{C}$ in FPLA-C33 and FPLA-C53 should be increased by $3 \%$ and $5 \%$ above that of the $30 \%$ BC-m addition, whereas the actual $\mathrm{C}$ values in the residue of these composites were $41.62 \%$ and $44.02 \%$, respectively. A higher percentage of elemental C means that more organic matter in the composite remained after combustion testing. The results add further evidence that CS behaves cooperatively with BC-m dispersed in the PLA matrix leading to the formation of a denser and more stable expanded char layer structure containing $\mathrm{P}$ and $\mathrm{N}$ reflected in the detection of $\mathrm{C}-\mathrm{O}-\mathrm{P}, \mathrm{P}-\mathrm{O}-\mathrm{P}$, and $\mathrm{C}-\mathrm{N}$. 

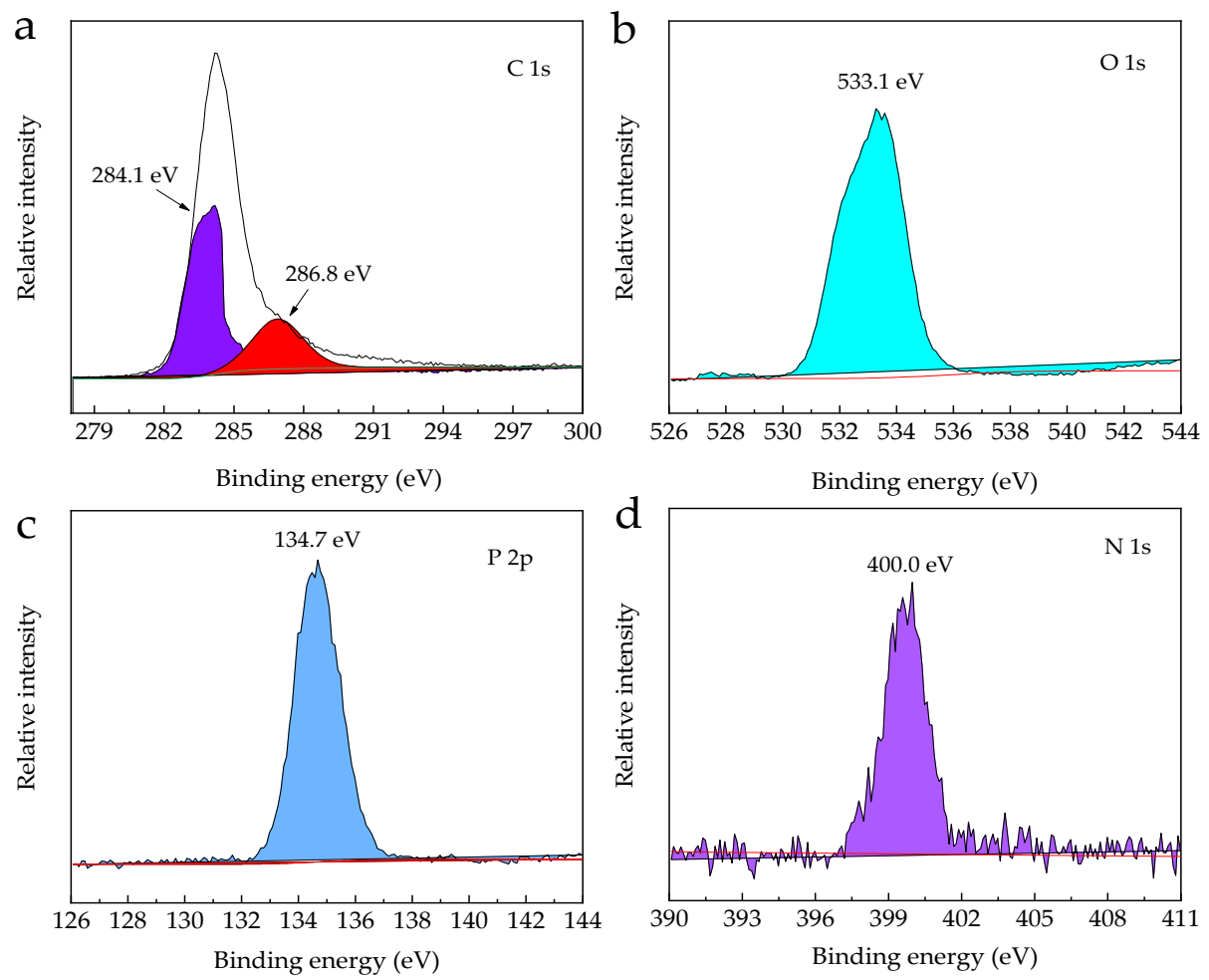

Figure 15. Spectra for char residues of FPLA-C53: (a) C 1s, (b) O 1s, (c) P 2p, and (d) N 1s.

\section{Conclusions}

(1) Co-adding 3 or $5 \mathrm{wt} . \%$ CS with BC-m to PLA enhanced tensile properties of PLA. CS is an interfacial adhesion promoter which improves the interfacial compatibility between BC-m and PLA. Adding $3 \mathrm{wt} . \% \mathrm{CS}$ and $30 \mathrm{wt} . \%$ BC-m increased the crystallinity to $38.92 \%$ or 43 times that of pure PLA $(0.9 \%)$. The internal crystal structure was reorganized by CS addition and the crystallinity index was increased.

(2) TGA showed early thermal degradation of CS-added PLA/BC-m composites and enhanced residue mass. In nitrogen atmosphere co-adding $5 \mathrm{wt} . \% \mathrm{CS}$ and $20 \mathrm{wt} . \%$ BC-m, the corresponding residue $(29.4 \%)$ was $55.1 \%$ higher than the theoretical value $(18.97 \%)$.

(3) Co-adding 5 wt. $\%$ CS and 30 wt. $\%$ BC-m, increased LOI to 33.6 vol\%; 4.7\% higher than adding BC-m alone. UL-94 V-0 rating at low BC-m addition (10 wt.\%) was improved correspondingly. Cooperative effectiveness analysis (Ce) on LOI results suggest that active cooperation between CS and BC-m improves the flame retardancy of PLA/BC-m composites.

(4) CONE results showed very effective further combustion suppression with just $3 \%$ CS co-addition to the effective baseline of $20 \%$ or more BC-m addition. For example peak heat release rate (pHRR) was reduced by almost $27 \%$ for $3 \% \mathrm{CS}+20 \% \mathrm{BC}-\mathrm{m}$, and total heat release (THR) was reduced by $30.5 \%$. Analysis of char morphology, chemical elements, and structure reveals that CS and BC-m form a denser, more stable carbonized layer that is effective in heat and oxygen insulation, resulting in improved flame retardancy of PLA composites.

(5) A mix of just $20 \mathrm{wt} . \% \mathrm{BC}-\mathrm{m}+3 \mathrm{wt} . \%$ CS may be a viable flame-retardant system that meets the requirements for a non-toxic, strong and biodegradable PLA packaging product. 
Author Contributions: The initial conceptualization and methodology of this project were conceived and originated by W.Z. and W.L., providing resources as well. Experiments were performed by L.Z., W.C. and W.L. and the data curation management was done by L.Z., W.C. and L.L., who completed the data curation. The original draft was written by W.L. and L.Z. with help of K.S. and N.Y. The manuscript was reviewed and edited by W.Z., K.S. and C.D. The supervision and project administration were performed by W.Z., W.L. and L.Z. The funding acquisition was supported by W.Z. and C.D. All authors have read and agreed to the published version of the manuscript.

Funding: This research was supported by key development projects of Zhejiang Province (2018C02008) and by Natural Sciences and Engineering Research Council of Canada (NSERC) through a Discovery Grant.

Institutional Review Board Statement: Not applicable.

Informed Consent Statement: Not applicable.

Data Availability Statement: The processed data required to reproduce these findings cannot be shared at this time since the data also contribute to part of an ongoing study.

Acknowledgments: The authors would like to acknowledge the Zhejiang Natural Science Foundation for the financial support of this research and the Zhejiang Academy of Forestry for the technical assistance. Financial support from Natural Sciences and Engineering Research Council of Canada (NSERC) through a discovery grant is also gratefully acknowledged.

Conflicts of Interest: The authors declare no conflict of interest.

\section{References}

1. Zhou, X.; Li, J.; Wu, Y. Synergistic effect of aluminum hypophosphite and intumescent flame-retardants in polylactide. Polym. Adv. Technol. 2015, 26, 255-265. [CrossRef]

2. Gu, L.; Qiu, J.; Qiu, C.; Yao, Y.; Sakai, E.; Yang, L. Mechanical properties and degrading behaviors of aluminum hypophosphitepoly (Lactic Acid) (PLA) nanocomposites. Polym. Plast. Technol. Mater. 2019, 58, 126-138. [CrossRef]

3. Nurul Fazita, M.R.; Jayaraman, K.; Bhattacharyya, D.; Mohamad Haafiz, M.K.; Saurabh, C.K.; Hussin, M.H.; HPS, A.K. Green composites made of bamboo fabric and poly (lactic) acid for packaging applications-A review. Materials 2016, 9, 435. [CrossRef] [PubMed]

4. Hwang, S.W.; Shim, J.K.; Selke, S.E.; Soto-Valdez, H.; Matuana, L.; Rubino, M.; Auras, R. Poly (L-lactic acid) with added $\alpha$-tocopherol and resveratrol: Optical, physical, thermal and mechanical properties. Polym. Int. 2012, 61, 418-425. [CrossRef]

5. Armentano, I.; Bitinis, N.; Fortunati, E.; Mattioli, S.; Rescignano, N.; Verdejo, R.; Lopez-Manchadob, M.A.; Kenny, J.M. Multifunctional nanostructured PLA materials for packaging and tissue engineering. Prog. Polym. Sci. 2013, 38, 1720-1747. [CrossRef]

6. Graupner, N.; Herrmann, A.S.; Müssig, J. Natural and man-made cellulose fibre-reinforced poly (lactic acid)(PLA) composites: An overview about mechanical characteristics and application areas. Compos. Part A Appl. Sci. Manuf. 2009, 40, 810-821. [CrossRef]

7. Zhan, J.; Liu, X.; Cao, C. Synergistic effect of OZrP on the combustion properties and thermal degradation behavior of intumescent flame retardant polylactide. In IOP Conference Series: Materials Science and Engineering; IOP: London, UK, 2020; Volume 740, p. 012070.

8. Senatov, F.S.; Niaza, K.V.; Zadorozhnyy, M.Y.; Maksimkin, A.V.; Kaloshkin, S.D.; Estrin, Y.Z. Mechanical properties and shape memory effect of 3D-printed PLA-based porous scaffolds. J. Mech. Behav. Biomed. Mater. 2016, 57, 139-148. [CrossRef]

9. Li, S.; Yuan, H.; Yu, T.; Yuan, W.; Ren, J. Flame-retardancy and anti-dripping effects of intumescent flame-retardant incorporating montmorillonite on poly(lactic acid). Polym. Adv. Technol. 2009, 20, 1114-1120. [CrossRef]

10. Tang, G.; Wang, X.; Xing, W.; Zhang, P.; Wang, B.; Hong, N.; Yang, W.; Hu, Y.; Song, L. Thermal degradation and flame retardance of biobased polylactide composites based on aluminum hypophosphite. Ind. Eng. Chem. Res. 2012, 51, 12009-12016. [CrossRef]

11. Laoutid, F.; Bonnaud, L.; Alexandre, M.; Lopez-Cuesta, J.M.; Dubois, P. New prospects in flame-retardant polymer materials: From fundamentals to nanocomposites. Mater. Sci. Eng. R Rep. 2009, 63, 100-125. [CrossRef]

12. Li, L.; Mao, X.; Ju, R.; Chen, Y.; Qian, L. Synergistic effect of organo-montmorillonite on intumescent flame-retardant PLA. Ferroelectrics 2018, 527, 25-36. [CrossRef]

13. Gu, L.; Qiu, J.; Yao, Y.; Sakai, E.; Yang, L. Functionalized MWCNTs modified flame retardant PLA nanocomposites and cold rolling process for improving mechanical properties. Compos. Sci. Technol. 2018, 161, 39-49. [CrossRef]

14. Vahabi, H.; Shabanian, M.; Aryanasab, F.; Mangin, R.; Laoutid, F.; Saeb, M.R. Inclusion of modified lignocellulose and nanohydroxyapatite in development of new bio-based adjuvant flame retardant for poly (lactic acid). Thermochim. Acta 2018, 666, 51-59. [CrossRef]

15. Shabanian, M.; Hajibeygi, M.; Hedayati, K.; Khaleghi, M.; Khonakdar, H.A. New ternary PLA/organoclay-hydrogel nanocomposites: Design, preparation and study on thermal, combustion and mechanical properties. Mater. Des. 2016, 110, 811-820. [CrossRef]

16. Wang, S.; Zhang, L.; Semple, K.; Zhang, M.; Zhang, W.; Dai, C. Development of biodegradable flame-retardant bamboo charcoal composites, Part I: Thermal and elemental analyses. Polymers 2020, 12, 2217. [CrossRef] 
17. Wang, S.; Zhang, L.; Semple, K.; Zhang, M.; Zhang, W.; Dai, C. Development of biodegradable flame-retardant bamboo charcoal composites, Part II: Thermal degradation, gas phase, and elemental analyses. Polymers 2020, 12, 2238. [CrossRef] [PubMed]

18. Zhang, L.; Chai, W.; Li, W.; Kate Semple k Yin, N.; Zhang, W.; Dai, C. Intumescent-Grafted Bamboo Charcoal: A Natural Nontoxic Fire-Retardant Filler for Polylactic Acid (PLA) Composites; ACS OMEGA: Washington, DC, USA, 2021; in press.

19. Feng, C.; Liang, M.; Jiang, J.; Huang, J.; Liu, H. Flame retardant properties and mechanism of an efficient intumescent flame retardant PLA composites. Polym. Adv. Technol. 2016, 27, 693-700. [CrossRef]

20. Zhang, T.; Yan, H.; Shen, L.; Fang, Z.; Zhang, X.; Wang, J.; Zhang, B. Chitosan/phytic acid polyelectrolyte complex: A green and renewable intumescent flame retardant system for ethylene-vinyl acetate copolymer. Ind. Eng. Chem. Res. 2014, 53, 19199-19207. [CrossRef]

21. Shi, X.; Jiang, S.; Hu, Y.; Peng, X.; Yang, H.; Qian, X. Phosphorylated chitosan-cobalt complex: A novel green flame retardant for polylactic acid. Polym. Adv. Technol. 2018, 29, 860-866. [CrossRef]

22. Wang, X.; Xing, W.; Wang, B.; Wen, P.; Song, L.; Hu, Y.; Zhang, P. Comparative study on the effect of beta-cyclodextrin and polypseudorotaxane as carbon sources on the thermalstability and flame-retardance of polylactic acid. Ind. Eng. Chem. Res. 2013, 52, 3287-3294. [CrossRef]

23. Wang, J.; Ren, Q.; Zheng, W.; Zhai, W. Improved flame-retardant properties of poly(lactic acid) foams using starch as a natural charring agent. Ind. Eng. Chem. Res. 2014, 53, 1422-1430. [CrossRef]

24. Zhang, R.; Xiao, X.; Tai, Q.; Huang, H.; Hu, Y. Modification of lignin and its application as char agent in intumescent flameretardant poly(lactic acid). Polym. Eng. Sci. 2012, 52, 2620-2626. [CrossRef]

25. Réti, C.; Casetta, M.; Duquesne, S.; Bourbigot, S.; Delobel, R. Flammability properties of intumescent PLA including starch and lignin. Polym. Adv. Technol. 2008, 19, 628-635. [CrossRef]

26. Costes, L.; Laoutid, F.; Brohez, S.; Dubois, P. Bio-based flame retardants: When nature meets fire protection. Mater. Sci. Eng. R Rep. 2017, 117, 1-25. [CrossRef]

27. Amri, F.; Husseinsyah, S.; Hussin, K. Mechanical, morphological and thermal properties of chitosan filled polypropylene composites: The effect of binary modifying agents. Compos. Part A Appl. Sci. Manuf. 2013, 46, 89-95. [CrossRef]

28. Thakur, V.K.; Thakur, M.K. Recent advances in graft copolymerization and applications of chitosan: A review. ACS Sustain. Chem. Eng. 2014, 2, 2637-2652. [CrossRef]

29. Chen, C.; Gu, X.; Jin, X.; Sun, J.; Zhang, S. The effect of chitosan on the flammability and thermal stability of polylactic acid/ammonium polyphosphate biocomposites. Carbohydr. Polym. 2017, 157, 1586-1593. [CrossRef]

30. Bertolino, V.; Cavallaro, G.; Milioto, S.; Lazzara, G. Polysaccharides/Halloysite nanotubes for smart bionanocomposite materials. Carbohydr. Polym. 2020, 245, 116502. [CrossRef] [PubMed]

31. Cavallaro, G.; Micciulla, S.; Chiappisi, L.; Lazzara, G. Chitosan-based smart hybrid materials: A physico-chemical perspective. J. Mater. Chem. B 2021, 9, 597-611. [CrossRef] [PubMed]

32. Hu, S.; Song, L.; Pan, H.; Hu, Y. Thermal properties and combustion behaviors of chitosan based flame retardant combining phosphorus and nickel. Ind. Eng. Chem. Res. 2012, 51, 3663-3669. [CrossRef]

33. Fang, F.; Zhang, X.; Meng, Y.; Gu, Z.; Bao, C.; Ding, X.; Li, S.; Chen, X.; Tian, X. Intumescent flame retardant coatings on cotton fabric of chitosan and ammonium polyphosphate via layer-by-layer assembly. Surf. Coat. Technol. 2015, 262, 9-14. [CrossRef]

34. Hu, S.; Song, L.; Pan, H.; Hu, Y.; Gong, X. Thermal properties and combustion behaviors of flame retarded epoxy acrylate with a chitosan based flame retardant containing phosphorus and acrylate structure. J. Anal. Appl. Pyrolysis 2012, 97, 109-115. [CrossRef]

35. Qian, S.; Sheng, K.; Yao, W.; Yu, H. Poly (lactic acid) biocomposites reinforced with ultrafine bamboo-char: Morphology, mechanical, thermal, and water absorption properties. J. Appl. Polym. Sci. 2016, 133, 43425. [CrossRef]

36. Standard Test Method for Plastics-Determination of Burning Behaviour by Oxygen Index; ISO 4589-2; ISO: Geneva, Switzerland, 2017.

37. Standard Test Method for Measuring the Comparative Burning Characteristics of Solid Plastics in A Vertical Position; ATSM D3801-10; ASTM: Philadelphia, PA, USA, 2020.

38. Reaction to Fire Tests-Heat Release, Smoke Production and Mass Loss Rate; ISO 5660-1; ISO: Geneva, Switzerland, 2015.

39. Ho, M.P.; Lau, K.T.; Wang, H.; Hui, D. Improvement on the properties of polylactic acid (PLA) using bamboo charcoal particles. Compos. Part B Eng. 2015, 81, 14-25. [CrossRef]

40. Halász, K.; Csóka, L. Plasticized biodegradable poly (lactic acid) based composites containing cellulose in micro-and nanosize. J. Eng. 2013, 329379. [CrossRef]

41. Zhai, W.; Ko, Y.; Zhu, W.; Wong, A.; Park, C.B. A study of the crystallization, melting, and foaming behaviors of polylactic acid in compressed CO2. Int. J. Mol. Sci. 2009, 10, 5381-5397. [CrossRef] [PubMed]

42. Yasuniwa, M.; Tsubakihara, S.; Iura, K.; Ono, Y.; Dan, Y.; Takahashi, K. Crystallization behavior of poly (L-lactic acid). Polymer 2006, 47, 7554-7563. [CrossRef]

43. Spiridon, I.; Paduraru, O.M.; Zaltariov, M.F.; Darie, R.N. Influence of keratin on polylactic acid/chitosan composite properties Behavior upon accelerated weathering. Ind. Eng. Chem. Res. 2013, 52, 9822-9833. [CrossRef]

44. Mihai, M.; Huneault, M.A.; Favis, B.D. Crystallinity development in cellular poly (lactic acid) in the presence of supercritical carbon dioxide. J. Appl. Polym. Sci. 2009, 113, 2920-2932. [CrossRef]

45. Bian, Y.; Han, C.; Han, L.; Lin, H.; Zhang, H.; Bian, J.; Dong, L. Toughening mechanism behind intriguing stress-strain curves in tensile tests of highly enhanced compatibilization of biodegradable poly (lactic acid)/poly (3-hydroxybutyrate-co-4hydroxybutyrate) blends. RSC Adv. 2014, 4, 41722-41733. [CrossRef] 
46. Zhang, Y.Z.; Su, B.; Ramakrishna, S.; Lim, C.T. Chitosan nanofibers from an easily electrospinnable UHMWPEO-doped chitosan solution system. Biomacromolecules 2008, 9, 136-141. [CrossRef]

47. Boonyeun, N.; Rujiravanit, R.; Saito, N. Deposition of carbon-tungsten carbide on coir pulp to improve its compatibility with polylactic acid. Cellulose 2021, 28, 4119-4136. [CrossRef]

48. Husseinsyah, S.; Amri, F.; Husin, K.; Ismail, H. Mechanical and thermal properties of chitosan-filled polypropylene composites: The effect of acrylic acid. J. Vinyl Addit. Technol. 2011, 17, 125-131. [CrossRef]

49. Shukor, F.; Hassan, A.; Islam, M.S.; Mokhtar, M.; Hasan, M. Effect of ammonium polyphosphate on flame-retardancy, thermal stability and mechanical properties of alkali treated kenaf fiber filled PLA biocomposites. Mater. Des. 2014, 54, 425-429. [CrossRef]

50. Jing, J.; Zhang, Y.; Tang, X.; Zhou, Y.; Li, X.; Kandola, B.K.; Fang, Z. Layer by layer deposition of polyethylenimine and bio-based polyphosphate on ammonium polyphosphate: A novel hybrid for simultaneously improving the flame-retardancy and toughness of polylactic acid. Polymer 2017, 108, 361-371. [CrossRef]

51. Lewin, M.; Weil, E.D. Mechanisms and modes of action in flame retardancy of polymers. Fire Retard. Mater. 2001, 1, 31-68.

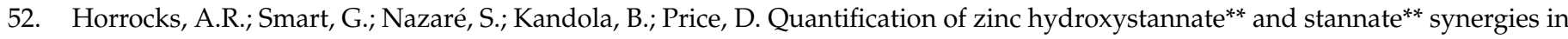
halogen-containing flame-retardant polymeric formulations. J. Fire Sci. 2010, 28, 217-248. [CrossRef]

53. Schartel, B.; Bartholmai, M.; Knoll, U. Some comments on the use of cone calorimeter data. Polym. Degrad. Stab. 2005, 88, 540-547. [CrossRef]

54. Kim, H.; Kim, D.W.; Vasagar, V.; Ha, H.; Nazarenko, S.; Ellison, C.J. Polydopamine-graphene oxide flame retardant nanocoatings applied via an aqueous liquid crystalline scaffold. Adv. Funct. Mater. 2018, 28, 1803172. [CrossRef]

55. Hassan, M.; Nour, M.; Abdelmonem, Y.; Makhlouf, G.; Abdelkhalik, A. Synergistic effect of chitosan-based flame retardant and modified clay on the flammability properties of LLDPE. Polym. Degrad. Stab. 2016, 133, 8-15. [CrossRef]

56. Yin, W.; Chen, L.; Lu, F.; Song, P.; Dai, J.; Meng, L. Mechanically robust, flame-retardant poly (lactic acid) biocomposites via combining cellulose nanofibers and ammonium polyphosphate. ACS Omega 2018, 3, 5615-5626. [CrossRef]

57. Tang, G.; Zhang, R.; Wang, X.; Wang, B.; Song, L.; Hu, Y.; Gong, X. Enhancement of flame retardant performance of bio-based polylactic acid composites with the incorporation of aluminum hypophosphite and expanded graphite. J. Macromol. Sci. Part A 2013, 50, 255-269. [CrossRef]

58. Yu, Y.; Song, P.A.; Jin, C.; Fu, S.; Zhao, L.; Wu, Q.; Ye, J. Catalytic effects of nickel (cobalt or zinc) acetates on thermal and flammability properties of polypropylene-modified lignin composites. Ind. Eng. Chem. Res. 2012, 51, 12367-12374. [CrossRef]

59. Xu, B.; Ma, W.; Shao, L.; Qian, L.; Qiu, Y. Enhancement of an organic-metallic hybrid charring agent on flame retardancy of ethylene-vinyl acetate copolymer. R. Soc. Open Sci. 2019, 6, 181413. [CrossRef] [PubMed]

60. Prabhakar, M.N.; Raghavendra, G.M.; Vijaykumar, B.V.D.; Patil, K.; Seo, J.; Jung-il, S. Synthesis of a novel compound based on chitosan and ammonium polyphosphate for flame retardancy applications. Cellulose 2019, 26, 8801-8812. [CrossRef] 